\title{
Using a Duration-Based Schedule Performance Index to Monitor the Performance of Projects Including Estimating the Final Cost
}

Nooshin Yousefi

Follow this and additional works at: https://researchrepository.wvu.edu/etd

\section{Recommended Citation}

Yousefi, Nooshin, "Using a Duration-Based Schedule Performance Index to Monitor the Performance of Projects Including Estimating the Final Cost" (2016). Graduate Theses, Dissertations, and Problem Reports. 7015.

https://researchrepository.wvu.edu/etd/7015

This Thesis is protected by copyright and/or related rights. It has been brought to you by the The Research Repository @ WVU with permission from the rights-holder(s). You are free to use this Thesis in any way that is permitted by the copyright and related rights legislation that applies to your use. For other uses you must obtain permission from the rights-holder(s) directly, unless additional rights are indicated by a Creative Commons license in the record and/ or on the work itself. This Thesis has been accepted for inclusion in WVU Graduate Theses, Dissertations, and Problem Reports collection by an authorized administrator of The Research Repository @ WVU. For more information, please contact researchrepository@mail.wvu.edu. 
Using a Duration-Based Schedule Performance Index to Monitor the Performance of Projects Including Estimating the Final Cost

Nooshin Yousefi

Thesis submitted

to the Statler College of Engineering and Mineral Resource

At West Virginia University

in partial fulfillment of the requirements

for the degree of

Master of Science

in

Industrial Engineering

Kenneth Currie, Ph.D., Committee Chairperson

Majid Jaridi, Ph.D.

Feng Yang, Ph.D.

Department of Industrial Engineering \& Management Systems Engineering

Morgantown, West Virginia

2016

Keywords: Project Management, Earned Value Management, Earned Duration Management, Statistical process control charts, autocorrelation data

Copyright 2016, Yousefi 


\title{
ABSTRACT
}

\section{Using a Duration-Based Schedule performance Index to Monitor the Performance of Projects Including Estimating the Final cost}

\author{
Nooshin Yousefi
}

One of the main concerns of project managers is monitoring the schedule performance of construction projects. A project manager needs tools to not only understand the status of project schedule performance, but also to find the causes of delays and the corresponding corrective actions. Hence, discovering time deviations from the project plan provides more reliable project schedule control. Applying statistical quality control charts on the project schedule performance index is suggested in this study. The use of quality control charts in this research monitors the process plan and provides first alarms for applying changes by detecting the time deviations over the project duration. For the schedule performance, Earned Value Management (EVM) has been shown to be a very powerful tool. However, EVM calculations are monetary based, which provides some misleading results for measuring the duration of the project. Earned Duration Management (EDM) introduces a better metric for schedule performance that solves this illusory results of EVM by detecting cost and schedule performance measures. So, applying statistical quality control charts on the EDM's schedule performance index is recommended in this research. Moreover, because of changes to tasks to correct project delays, it becomes more difficult to estimate the final budget. So in this study, considering the time value of money, delay in employer payment and contractor cash flow in different phases of the construction projects, beside the use of EDM schedule index is suggested to calculate the final budget of the project. A construction case study illustrates the enhancement of the introduced method. 


\section{ACKNOWLEDGEMENTS}

Several people have been instrumental in allowing my thesis to be completed. I would like to thank especially Dr. Kenneth Currie, Professor and chairperson of the Industrial and Management System Engineering Department, for his encouragement and patience throughout the duration of my thesis. I would also like to thank Dr. Majid Jaridi, who generously shared his insightful idea and provided encouragement, and Dr. Feng Yang, who provided me thoughtful advice. 


\section{TABLE OF CONTENTS}

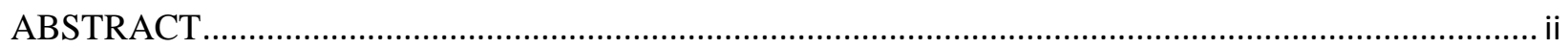

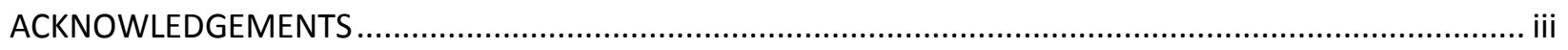

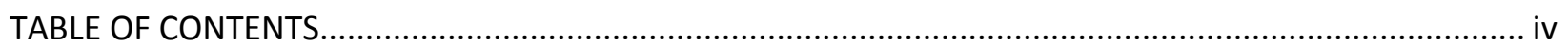

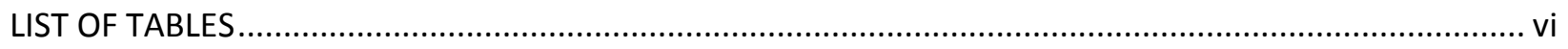

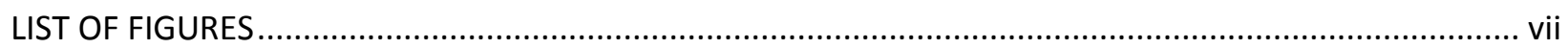

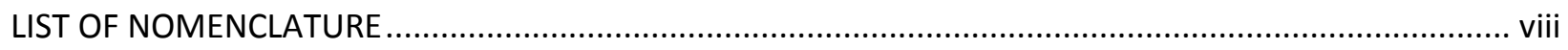

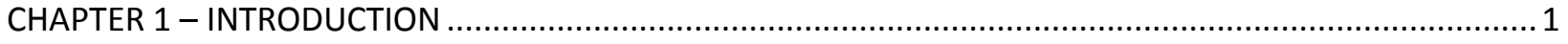

1.1.1 What is Earned Value Management? ................................................................................ 1

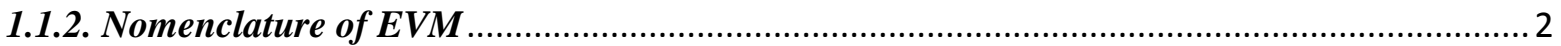

1.1.3 Brief review of Earned Duration Measurement Technique :............................................. 8

1.1.4. Considering financial aspects in estimating the final budget ............................................ 11

1.1.5. The Overview of Autoregressive Integrated Moving Average Models ................................ 12

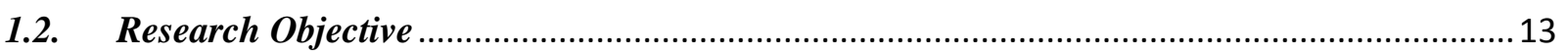

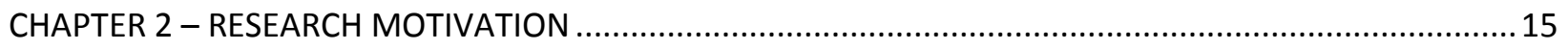

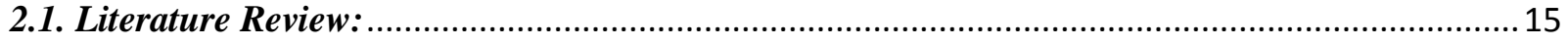

2.1.1 Evolution of Earned Value Management ........................................................................ 16

2.1.2 Review on cost and schedule performance in EVM: ........................................................ 17

2.1.3. Final estimation and forecasting in EVM: .................................................................... 19

2.1.4. Statistical Methods in Earned Value Management: .............................................................20

2.1.5. Considering financial factors in Earned Value Management ............................................ 21

2.1.6. Earned Duration Management ....................................................................................... 21

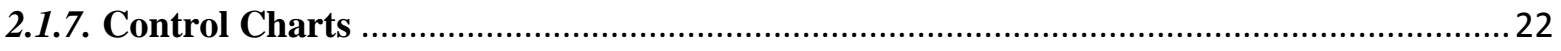

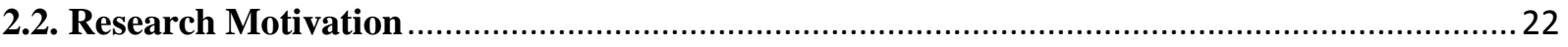

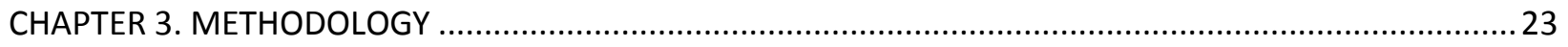

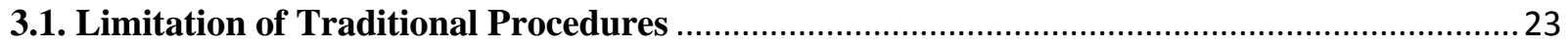

3.2 Duration-Based Parameters in Measuring the Project Schedule Performance ......................23

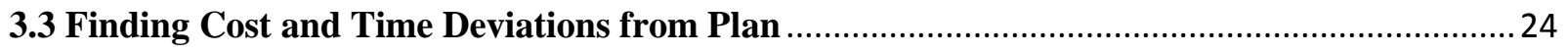

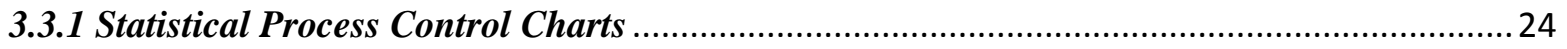

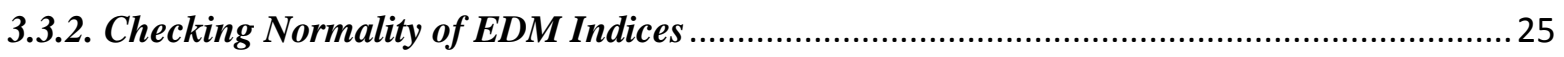

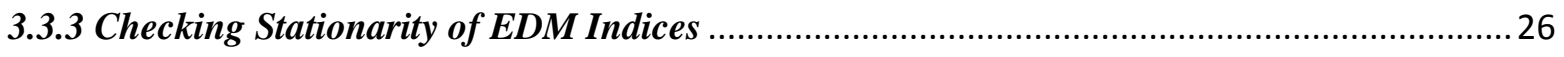




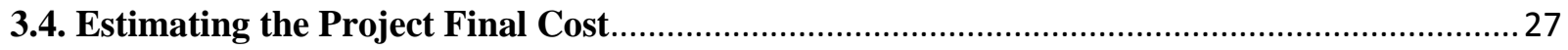

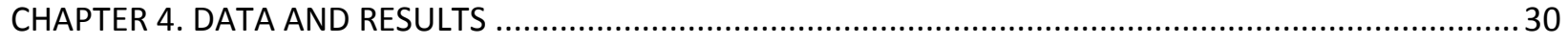

4.1. Applying Residual Control Charts for Monitoring the Cost and Schedule of Project ............30

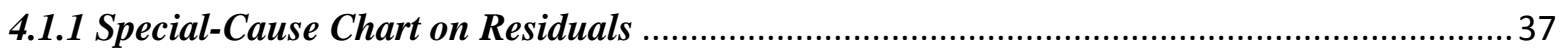

4.2. Case Study for Estimating the Project Final Cost .............................................................. 41

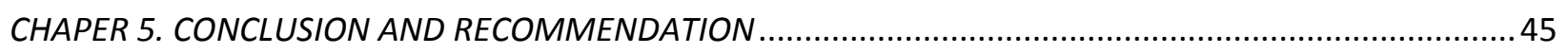

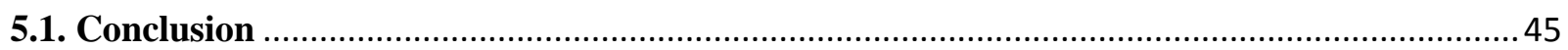

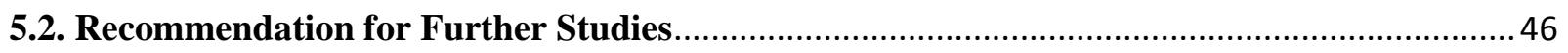

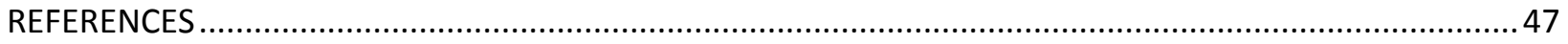

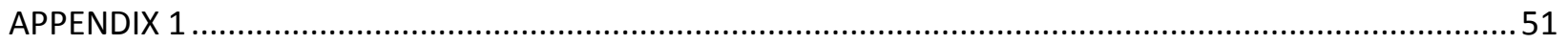

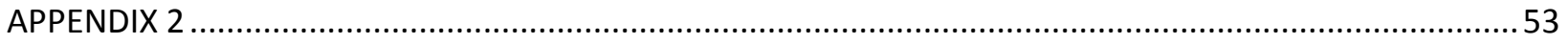




\section{LIST OF TABLES}

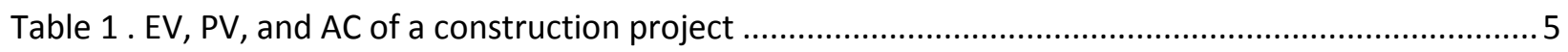

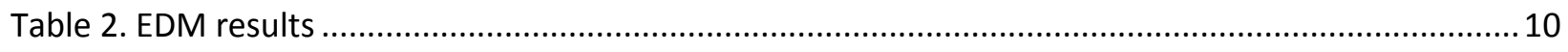

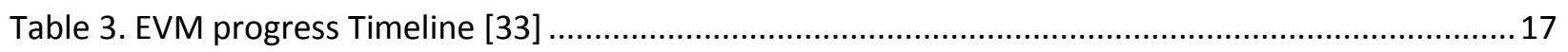

Table 4 Characteristics of theoretical ACF and PACF for process. [52] ................................................. 37

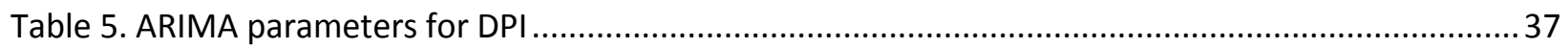

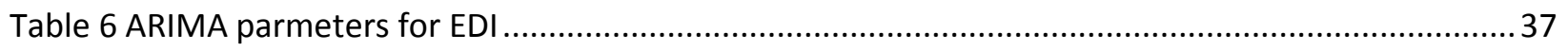

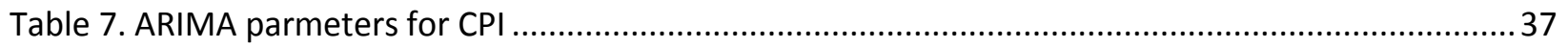

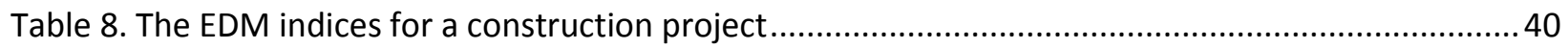

Table 9. Information about a construction project ............................................................................ 41

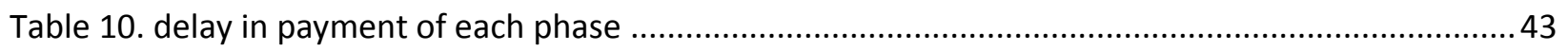

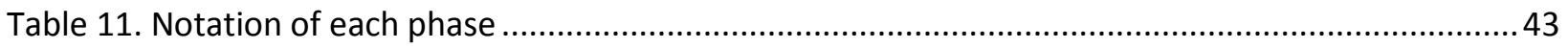

Table 12. Cost and schedule performance indices of a construction project .........................................51

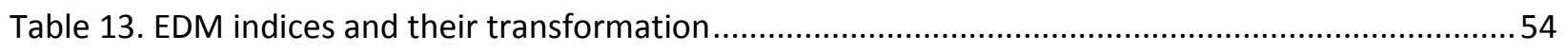

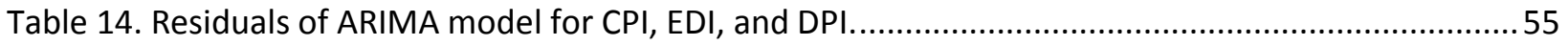




\section{LIST OF FIGURES}

Figure 1. Components of Earned Value Management [25] ........................................................... 4

Figure 2. Microsoft Project report[2] ............................................................................................ 7

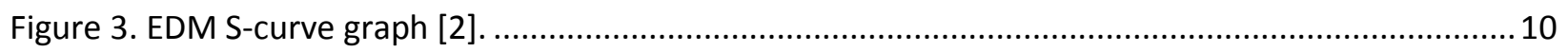

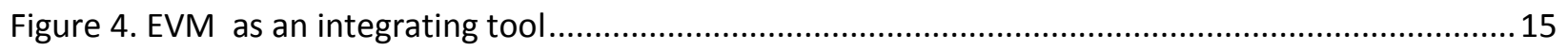

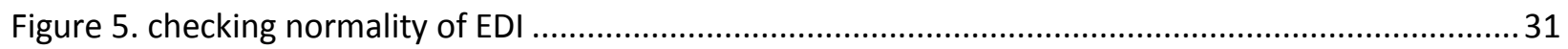

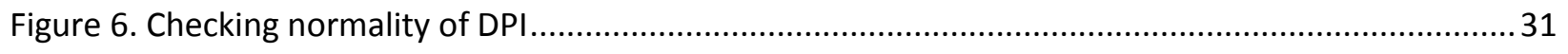

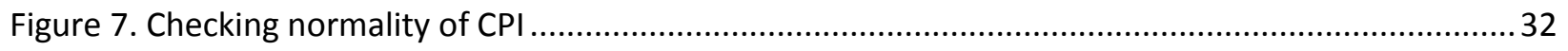

Figure 8. Time series plot for EDI before and after one lag differencing..............................................32

Figure 9. Time series plot for DPI transformed before and after one lag differencing ............................ 33

Figure 10. Time series plot for CPI transformed before and after one lag differencing............................33

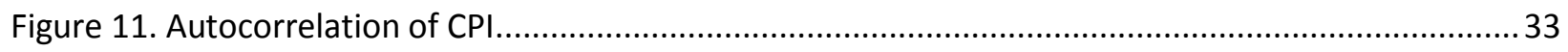

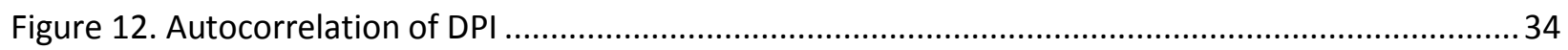

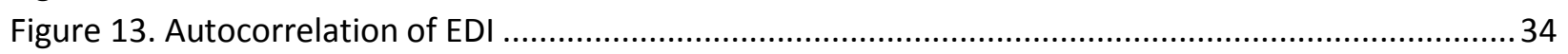

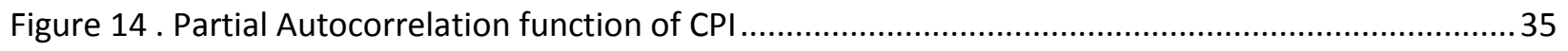

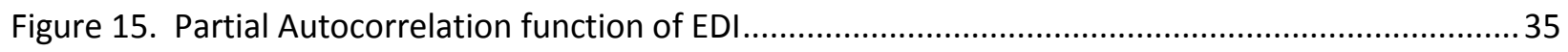

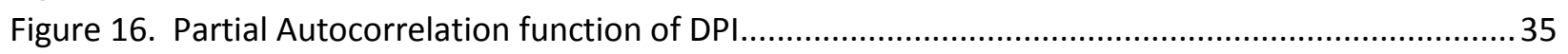

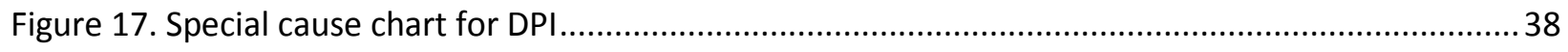

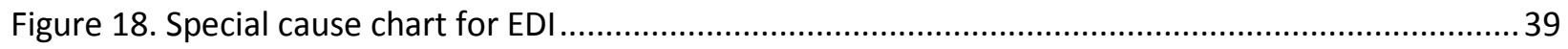

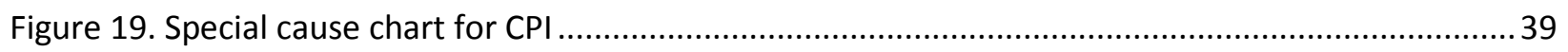

Figure 20. Estimated final budget by different methods .................................................................. 42

Figure 21. The effect of delay in payment on estimating final budget.....................................................43

Figure 22. The effect of Interest Rate on estimating final budget...................................................... 44

Figure 23. Summary of Johnson transformation for DPI .................................................................... 53

Figure 24. Summary of Johnson transformation for CPI..................................................................... 53 


\section{LIST OF NOMENCLATURE}

$\varepsilon_{\mathrm{t}}$

$\mathrm{AC}$

$\mathrm{ACF}$

AD

ARIMA

ARMA

AT

BAC

$\mathrm{CCC}$

$\mathrm{CM}$

$\mathrm{COV}$

CP

CPI

CUSUM

$\mathrm{CV}$

D

DPI

EAC

ED

$\mathrm{ED}(\mathrm{t})$

EDI

EDM

EM

EMWA

ES

ETC

$\mathrm{EV}$

EVM

FPI

i

LCL

PACF

PD

PV

SCC

SPC

SPI
Noise at time $\mathrm{t}$

Actual cost

Autocorrelation function

Actual duration

Autoregressive Integrated Moving Average

Autoregressive Moving Average

Actual time

Budget at completion

Common cause chart

Cash money

Covariance

Contract price

Cost performance index

Cumulative Sum

Cost variance

Delay in payment

Duration performance index

Estimate at completion

Earned duration

Earned duration at time $\mathrm{t}$

Earned duration index

Earned duration management

Earned money

Exponentially Weighted Moving Average

Earned schedule

Estimate to complete

Earned value

Earned value management

Financial performance index

Interest rate

Lower control limit

Partial autocorrelation function

Planned duration

Planned value

Special cause chart

Statistical process control

Schedule performance index 


$\begin{array}{ll}\text { SPI }(\mathrm{t}) & \text { Schedule performance index at time } \mathrm{t} \\ \mathrm{SV} & \text { Schedule variance } \\ \text { TED } & \text { Total earned duration } \\ \text { TPD } & \text { Total planned duration } \\ \mathrm{UCL} & \text { Upper control limit } \\ \text { Var } & \text { Variance } \\ \mathrm{Yt} & \text { Time series at time } \mathrm{t} \\ \phi & \text { The autoregressive parameter } \\ \mu & \text { Population mean } \\ \omega & \text { The moving average parameter }\end{array}$




\section{CHAPTER 1 - INTRODUCTION}

\subsection{Introduction}

Project management is the application of processes, methods, knowledge, skills and experience to achieve the project objectives. A project is a transient endeavor to achieve a planned objective. It has a range of processes that occur throughout its life. A project is said to be a success if it is completed within the planned timescale and budget. According to the complexity of a project, they require professional managers to come together to focus on specific project objectives. A project manager needs a wide range of skills; often technical skills, certainly people management skills and good business awareness. Project managers define the project based upon customer objectives, including the list of project deliverables and a set of activities. Project management is concerned with managing discrete packages of work to achieve objectives. There are a wide variety of factors that impact effective management of projects. The location of projects, their level of complexity, the total budget of projects and the human resources are examples of these factors. However, the primary question that should be addressed of any project, "Is the project going to finish within the allowable budget and within the time scheduled?" All of these questions come to mind because additional cost would be incurred if the project doesn't perform well, hence within budget and time scheduled to finish. Earned Value Management is a useful tool and can help project managers track their projects.

\subsubsection{What is Earned Value Management?}

In this chapter, the evolution of Earned Value Management (EVM) with its key elements and concepts is explained. Earned value is expressed in terms of the given budget that is assigned to that work for a schedule activity or work breakdown structure component. EVM is the most effective performance measurement and feedback tool for managing projects according to the Project Management Body of Knowledge $\left(\mathrm{PMBOK}^{\circledR}\right)$ Guide. The PMBOK defines EVM as a project management methodology for integrating scope, schedule, and resources, and for objectively measuring project performance and progress. Project performance and progress could be anticipated and foreseen by comparing the current indices with the predefined indices of the project. So, Earned Value is a program management technique that uses "work in progress" to indicate what will happen to work in the future. It allows projects to be managed better on time 
and budget. Therefore, it can be said that EVM System is not a specific system or tool, but rather, a set of guidelines that guide project managers to control system.

\subsubsection{Nomenclature of EVM}

The following parameters are the basic elements of EVM system.

Planned value (PV): PV, or the Budgeted Cost for Work Scheduled (BCWS), is the sum of budgets for all planned work scheduled to be accomplished within a given time.

Budget at Completion (BAC): BAC is the cumulative sum for all Budgeted Costs of Work Scheduled and represents the original estimate of the cost for a project.

Earned Value (EV): the EV or Budgeted Cost of Work Performed (BCWP) is the sum of the approved budgets for activities or portions of activities completed during a given time.

Actual Cost (AC): AC or Actual Cost of Work Performed (ACWP) are the costs that are paid for accomplishing the tasks performed on a project within a given time period. This includes charges for goods and services received and other assets acquired, such as invoices for work, material delivered, progress payments and fees/profit allocable to the contract.

Cost Variance (CV): This is the difference between the value of the work accomplished in terms of the baseline (EV) and the amount spent to accomplish the work (AC).

$\mathrm{CV}=\mathrm{EV}-\mathrm{AC}$

A negative $\mathrm{CV}$ is an indication of an unfavorable condition for the project.

Schedule Variance (SV): This is the algebraic difference between the value of the work accomplished in terms of the baseline (EV) and the amount of work that was planned (PV).

$\mathrm{SV}=\mathrm{EV}-\mathrm{PV}$

A negative SV is an indication of an unfavorable condition for the project.

Cost Performance Index (CPI): This is the ratio of the value of the work accomplished in terms of the baseline (EV) and the amount spent to accomplish the work (AC).

$C P I=\frac{E V}{A C}$ 
A CPI greater than one $(>1)$ indicates a favorable condition, while a performance measure with a CPI less than one $(<1)$ indicates an unfavorable condition.

Schedule Performance Index (SPI): This is the ratio of the value of the work accomplished in terms of the baseline (EV) and the amount of work that was planned (PV).

$S P I=\frac{E V}{P V}$

A SPI greater than one $(>1)$ indicates a favorable condition, while a performance measure with a SPI less than one $(<1)$ indicates an unfavorable condition.

Estimate to Complete (ETC): This is the expected cost needed to complete all the remaining work for activities of projects, where PI is the performance index, which can be SPI, CPI or a combination of these performance indices

$E T C=\frac{B A C-E V}{P I}$

Estimate at Completion (EAC): This is the expected total cost of all activities once the defined scope is completed. In fact, EAC is the estimated cost to complete the remainder of the work can be calculated based on a number of performance indices. EAC is equal to the AC plus the ETC for all remaining work.

$\mathrm{EAC}=\mathrm{AC}+\mathrm{ETC}$

Earned Schedule (ES): The duration from the beginning of the project to the date on which the PV should have been equal to the current value of EV. In Figure 2, it is the date at which the horizontal line through the current value of EV intersects the PV curve.

Actual Time (AT): The duration from the beginning of the project to the status date. AT has also been called the Actual Duration (AD).

The new Schedule Performance Index (SPI(t)): To improve the performance of SPI, the Earned Schedule method converts the Earned Value at a given point in time into its equivalent duration required to achieve that Planned Value. SPI $(\mathrm{t})$ is the new schedule performance index which is calculated as below:

$E S(t)=t+\frac{E V-P V_{t}}{P V_{t+1}-P V_{t}} \times 1($ calender unit $)$ 
$S P I(t)=\frac{E S(t)}{A D}$

S-Curve is a tool for that Project managers use to report the status of projects. Figure 1. Shows the Earned Value management elements graphically.

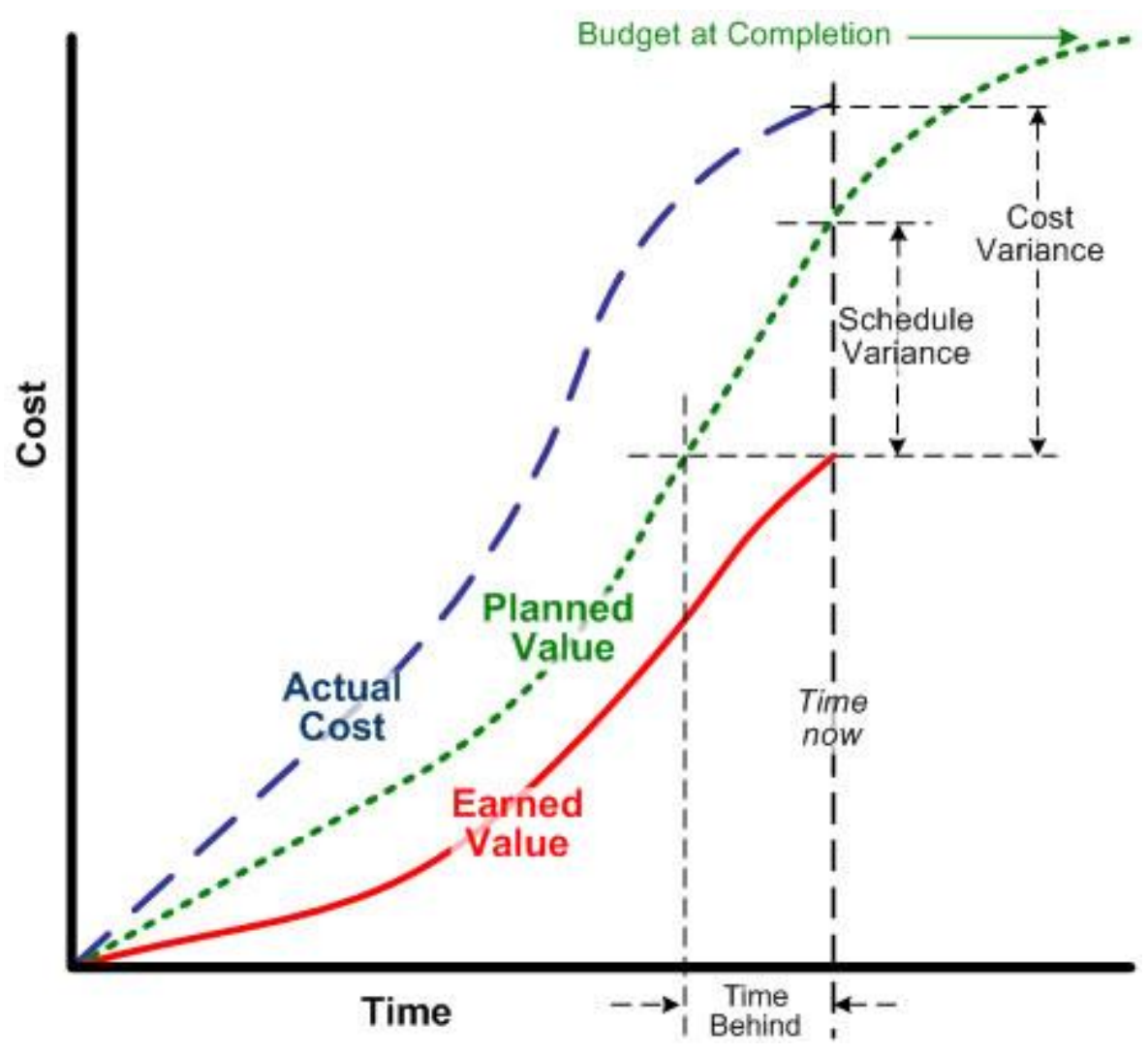

Figure 1. Components of Earned Value Management [25]

Earned Value Management (EVM) has been applied for several years for project planning, tracking, and decision-making. In addition, the reporting method of EVM is a great tool for communicating with managers and customers. It is a tool that integrates the cost, schedule and technical requirements of a project. EVM helps project managers in determining the current status of project by answering these kind of questions: Is the project on schedule? Is the project on budget? What are the time and cost variances? What are the estimates of completion after the project is underway?

Earned Value Management uses the SPI and SPI(t) for measuring the schedule performance of projects. Although the SPI $(\mathrm{t})$ is the preferred schedule index comparing to SPI, Khamooshi (2014) introduced some of its shortcomings which makes it inapplicable in all cases. Since in 
calculating SPI(t), the EV is used as the main proxy, it cannot solve the problem of being a monetary-based schedule performance index. Hence, performance measures which are costbased cannot be an accurate index for schedule attainment. Khamooshi (2014) brought an example of a construction project with high PV and short duration. In this example, there are two parallel paths. The longer path including activities A, B, and E, and the other path contains activity $\mathrm{C}$, and activity D (which has the highest Value). Figure 2 shows the EVM output of Microsoft Project report.

If all the activities are on plan and on budget, except activity B (on the critical path), which has not been started yet, the project should have a low schedule performance index, while producing the following SPI, and SPI $(\mathrm{t})$. Table 1 shows the information of this project.

Table 1.EV, PV, and AC of a construction project

\begin{tabular}{|c|c|c|c|}
\hline WEEK & EV & PV & AC \\
\hline $\mathbf{1}$ & 17,143 & 17,143 & 17,143 \\
\hline $\mathbf{2}$ & 34,286 & 34,286 & 34,286 \\
\hline $\mathbf{3}$ & 51,429 & 51,429 & 51,429 \\
\hline $\mathbf{4}$ & 68,571 & 68,571 & 68,571 \\
\hline $\mathbf{5}$ & 87,714 & 87,714 & 87,714 \\
\hline $\mathbf{6}$ & 106,857 & 106,857 & 106,857 \\
\hline $\mathbf{7}$ & 126,000 & 126,000 & 126,000 \\
\hline $\mathbf{8}$ & 138,000 & 140,500 & 138,000 \\
\hline $\mathbf{9}$ & 150,000 & 155,000 & 150,000 \\
\hline $\mathbf{1 0}$ & 162,000 & 169,500 & 162,000 \\
\hline $\mathbf{1 1}$ & 174,000 & 184,000 & 174,000 \\
\hline $\mathbf{1 2}$ & 186,000 & 198,500 & 186,000 \\
\hline $\mathbf{1 3}$ & 198,000 & 213,000 & 198,000 \\
\hline $\mathbf{1 4}$ & $\mathbf{2 1 0 , 0 0 0}$ & 227,500 & 210,000 \\
\hline & & & \\
\hline & & & \\
\hline
\end{tabular}




$$
\begin{aligned}
& S P I=\frac{E V}{P V}=\frac{210,000}{227,500}=0.92 \\
& S P I(t)=\frac{E S(t)}{A D}=\frac{13}{14}=0.93
\end{aligned}
$$

Therefore, it is evident that the indices 0.92 and 0.93 are relatively high performance, demonstrating that both the SPI and SPI(t) are cost-based, and not a good index for measuring the schedule performance of projects. To resolve this inaccuracy Khamooshi (2014) introduced a new approach called Earned Duration Management (EDM), which decouples the cost and schedule dimensions, and introduces a new index for schedule performance of project duration. 


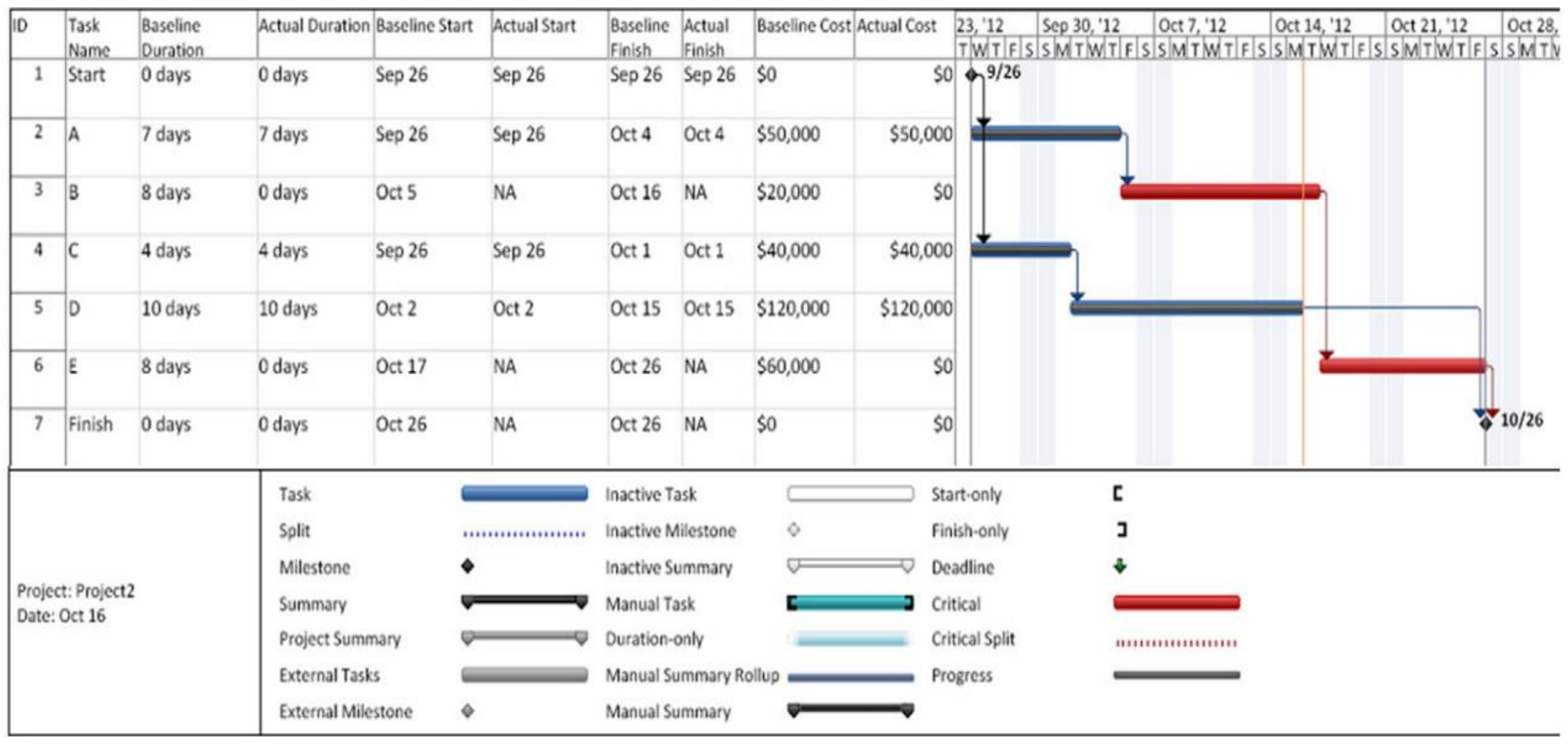

Figure 2. Microsoft Project report[2] 


\subsubsection{Brief review of Earned Duration Measurement Technique:}

EDM definitions and notations are contained into two categories of Micro or activity level and Macro or project level. By using this methodology project managers can evaluate and monitor project performance with more precision. Below are some EDM indices:

For measuring schedule performance, Duration Performance Index (DPI) represented by the the duration performance index for activity $i$ :

$$
D P I_{i}=\frac{E D_{i}}{A D_{i}}
$$

Where $\mathrm{ED}_{\mathrm{i}}$ is the Earned Duration for activity $i$ at the time $\mathrm{DPI}_{\mathrm{i}}$ is measured and $\mathrm{AD}_{\mathrm{i}}$ is the

actual duration spent for activity $i$. This index will compare to one if $D P I_{i}>1$ it indicates that the actual progress of activity $i$ is behind its planned schedule. And if it is less than one, it shows activity $i$ is ahead of planned one. When the schedule is on plan it will be equal to one. In fact it shows how well the activity is completing.

At the project (macro) level, the Duration Performance Index (DPI) represents how well the project is doing to be completed on time, which is considered in the critical path.

$$
D P I=\frac{E D(t)}{A D}
$$

$\mathrm{ED}(\mathrm{t})$ is the duration corresponding to Total Earned Duration on the duration S-curve (figure 3) and $\mathrm{AD}$ is the actual duration spent for the project. DPI is also being compared to one for evaluating the performance of the project according to what was planned. DPI greater than one, shows a good schedule performance, if it is lower than one it indicates poor schedule performance and, if the project is on plan, DPI should be equal to one.

EDI is the other schedule performance index Khamooshi (2014) demonstrated in his study. At the micro level we have the follow equation for activity $i$.

$$
E D I_{i}=\frac{E D_{i}}{P D_{i}}
$$

Where $\mathrm{ED}_{i}$ is the Earned Duration for activity $i$ at any point in time, and $\mathrm{PD}_{\mathrm{i}}$ is the duration which is planned for activity $i$. At the project (macro) level EDI is represented as follow: 


$$
E D I=\frac{T E D}{T P D}
$$

Where TED is the Total Earned Duration for any point in time, which is the sum of ED for all the activities in progress and completed. And Total Planned Duration (TPD) is the sum of PD for the activities in progress and completed. The comparison of Duration earned and planned is what EDI measures; indeed, it measures the schedule performance of the project. Since at any point in time, the project might have achieved more, less, or the same amount of work in comparison with the work planned to be achieved by that time, this index can have values of greater than one, lower than one or equal to one.

For evaluating the cost performance of project, we have the same equation as used in EVM. The Cost Performance Index (CPI) shown in equation 8 is a ratio of Earned Value (EV) to Actual Cost (AC)

$$
C P I=\frac{E V}{A C}
$$

CPI can be calculated for each point of time, so EV is the sum of the earned value of all completed and in progress activities to that point of time and $\mathrm{AC}$ is actual costs which spent for all the completed and in progress activities till that point of time. The value of CPI can be less than one for cases where the project is over the budget, greater than one when the project is under the budget and equal to one for cases where the project is on budget.

Using these new schedule performance indices for measuring the schedule of that construction project, we have following EDI and DPI. Table 2 represents the information of the same project.

$$
\begin{aligned}
& D P I=\frac{E D(t)}{A D} \sim \frac{11}{14}=0.79 \\
& E D I=\frac{T E D}{T P D}=\frac{21}{28}=0.75
\end{aligned}
$$


Table 2. EDM results

\begin{tabular}{|l|l|l|l|}
\hline Day & $\begin{array}{l}\text { Total earned } \\
\text { duration }\end{array}$ & $\begin{array}{l}\text { Total planned } \\
\text { duration }\end{array}$ & $\begin{array}{l}\text { Total actual } \\
\text { duration }\end{array}$ \\
\hline $\mathbf{1}$ & 2 & 2 & 2 \\
\hline $\mathbf{2}$ & 4 & 4 & 4 \\
\hline $\mathbf{3}$ & 6 & 6 & 6 \\
\hline $\mathbf{4}$ & 8 & 8 & 8 \\
\hline $\mathbf{5}$ & 10 & 10 & 10 \\
\hline $\mathbf{6}$ & 12 & 12 & 12 \\
\hline $\mathbf{7}$ & 14 & 14 & 14 \\
\hline $\mathbf{8}$ & 15 & 16 & 15 \\
\hline $\mathbf{9}$ & 16 & 18 & 16 \\
\hline $\mathbf{1 0}$ & 17 & 20 & 17 \\
\hline $\mathbf{1 1}$ & 18 & 22 & 18 \\
\hline $\mathbf{1 2}$ & 19 & 24 & 19 \\
\hline $\mathbf{1 3}$ & 20 & 26 & 20 \\
\hline $\mathbf{1 4}$ & 21 & 28 & 21 \\
\hline
\end{tabular}

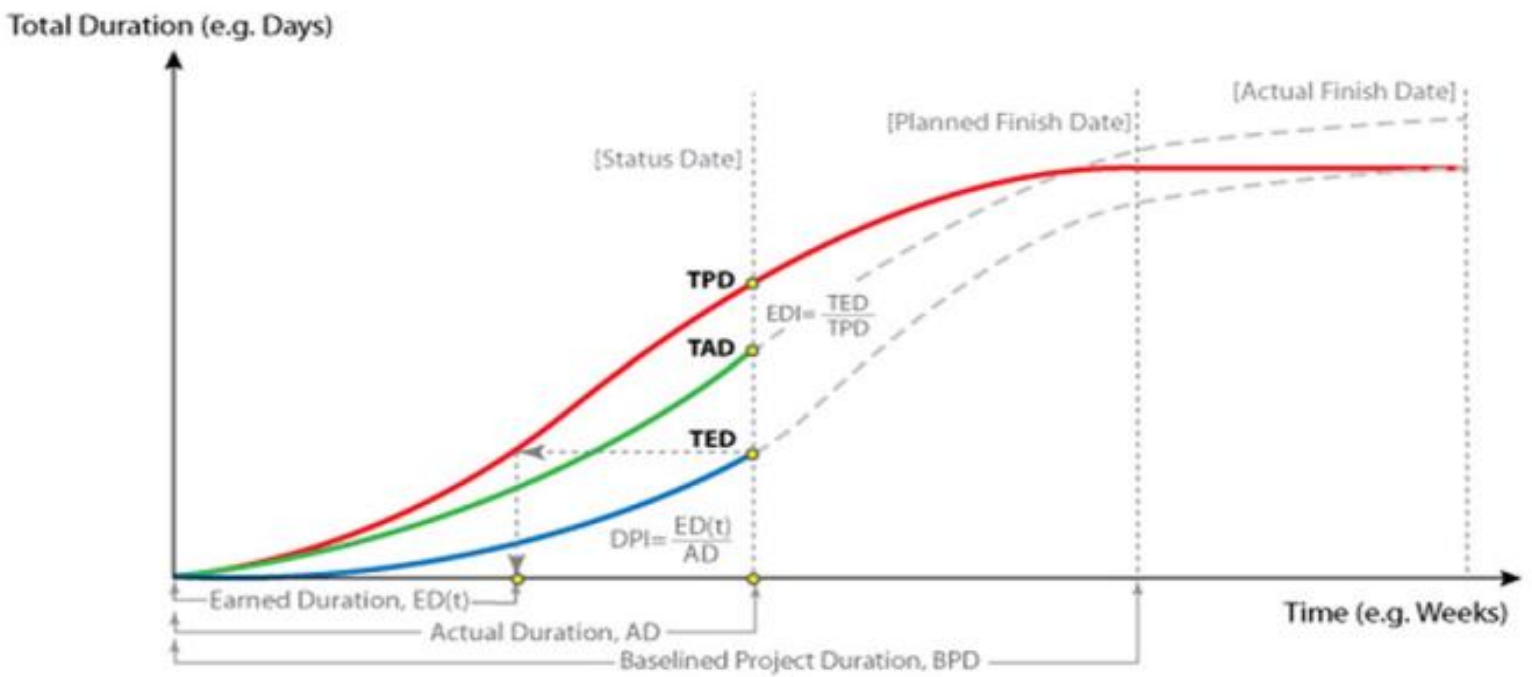

Figure 3. EDM S-curve graph [2]. 


\subsubsection{Considering financial aspects in estimating the final budget}

Estimating the final budget is one of the main uses of Earned Value Management (EVM). Many EVM studies fail to consider some events that impact the estimated final budget, such as delays in payment or the time value of money. Bagherpour (2011) introduced a model that estimates the final budget of projects which accounts for both the time value of money and delays in payment. The notation of parameters used in his method is introduced as below:

- CM : Cash Money

- CP : Contract Price

- EM : Earned Money

- FPI : Financial Performance Index

The CM is paid on the basis of CP throughout the project, and the CM should be calculated within the limits of the BAC. CP is normally included with BAC, contract deductions (such as tax and insurance) profits and organizational overhead. The EM is the earned money at the current point of time, according to the actual progress of the project, and it is calculated as shown in equation 14:

$E M=C M * \frac{B A C}{C P}$

The FPI can be calculated as shown in equation 15 by dividing the amount of money earned by the actual cost of the project up to the present time, AC. From a financial point of view, FPI $>1$ indicates a favorable position while FPI $<1$ indicates a less-than-favorable position. By using the FPI, the effects of financial issues are considered in the final budget estimate.

$F P I=\frac{E M}{A C}$

Equation 16 is useful for considering financial aspects such as delay in payment, cash flow and the time value of money. The first term is simply AC, as described above. The second term is the remaining budget that should be spent when considering the impacts of schedule, cost and the impacts of financial factors. The third term is the amount of money which is expected to be paid by the employer, but has not yet been paid 
$E A C=A C+\frac{B A C-E V}{W_{1} * S P I+W_{2} * C P I+W_{3} * F P I}+\frac{(E V-E M) *(1+i)^{D}-(E V-E M)}{F P I}$

$\mathrm{D}$ is the time delay in cash payment and $\mathrm{i}$ is the interest rate over the same time frame in which $\mathrm{D}$ is expressed. The amount of money that the employer has not paid is equal to (EV - EM), and $(\mathrm{EV}-\mathrm{EM})^{*}(1+\mathrm{i})^{\mathrm{D}}$ represents the time value of money. Therefore, subtracting $(\mathrm{EV}-\mathrm{EM})$ from $(\mathrm{EV}-\mathrm{EM})^{*}(1+\mathrm{i})^{\mathrm{D}}$ produces the extra money that should be paid by the employer for their delay. There exist two main deficiencies in the Bagherpour (2011) model. First, it considers the monetary-based index for the schedule performance, which may lead to inaccurate results. Second, he analyzed an entire construction project in one phase. In the real world, the different phases of a project need to be analyzed separately. The introduced model in this research is an attempt to overcome these drawbacks.

\subsubsection{Overview of Autoregressive Integrated Moving Average Models}

A time series is a set of observations, $\left\{y_{t}: t=1,2, \ldots, T\right\}$, usually considered to be discrete observations which are recorded at regular time intervals such as hourly, daily, monthly, or yearly. Box and Jenkins (1970) suggested a mathematical approach for forecasting time series, now called the Box-Jenkins technique. This technique is an integration of the autoregressive, and the moving average methods, which is called the ARIMA (Autoregressive Integrated Moving Average) model. It is a statistical method for analyzing the time series by modeling the correlations in the data. The combination of the autoregressive model and moving average model moves forward to ARIMA model.

\subsubsection{Autoregressive model}

In Autoregressive model each value of time series $Y_{t}$ depends only on the sum of the product of the previous values $Y_{t-1}, Y_{t-2}, \ldots, Y_{t-p}$ and the regression coefficient $\phi_{0}, \phi_{1}, \ldots, \phi_{p}$ and residual $\varepsilon_{t}$. The p-order autoregressive model is as following form:

$Y_{t}=\phi_{0}+\phi_{1} Y_{t-1}+\phi_{2} Y_{t-2}+\cdots+\phi_{p} Y_{t-p}+\varepsilon_{t}$

Where $Y_{t}$ is value of time series at time t. By adjusting the regression coefficients $\phi_{p}$, the Autoregressive model can be capable in as wide range variety of time series forecasting.

\subsubsection{Moving-Average Models}


In Moving-Average model, finding the mean for a specified set of values is the main idea to forecast the next period and correct any mistakes made in the last few forecasts. The general form of Moving-Average model is as follow:

$Y_{t}=w_{0}+\varepsilon_{t}-w_{1} \varepsilon_{t-1}-w_{2} \varepsilon_{t-2}-\cdots-w_{q} \varepsilon_{t-q}$

Where $Y_{t}$ is value of time series at time t. $w_{0}, w_{1}, w_{2}, \ldots, w_{q}$ are the weights applied to $\varepsilon_{t-1}, \varepsilon_{t-2}, \ldots, \varepsilon_{t-q}$ previous forecast errors, and $\varepsilon_{t}$ is the residual error. The Moving-Average model works well with stationary data, and time series without trends or seasonality.

\subsubsection{ARMA Models}

The mixture of MA and AR models provides e general models called ARMA. In ARMA(p,q) model, $\mathrm{p}$ is the number of autoregressive terms. And $\mathrm{q}$ is the number of lagged forecast errors.

$Y_{t}=\phi_{0}+\phi_{1} Y_{t-1}+\phi_{2} Y_{t-2}+\cdots+\phi_{p} Y_{t-p}+\varepsilon_{t}-w_{1} \varepsilon_{t-1}-w_{2} \varepsilon_{t-2}-\cdots-w_{q} \varepsilon_{t-q}$

The ARIMA(p,q) uses the combinations of past values and past forecasting errors and fits a model on time series which cannot be fitted by AR and MA models adequately.

\subsection{Research Objective}

In every project, project delays and budget overruns can greatly increase costs for the owner(s); hence, finding a more robust and reliable approach to predicting project cost and duration has been the main focus of researchers in this area in recent years. The aim of this research is to provide a method which can help project managers formulate a more realistic cost estimate. According to the economic conditions of a country, the time value of money changes over time, meaning that delays in payment to a contractor can cause more cost than it would under stable conditions. Therefore, the time value of money and delay in payment are factors that must be considered when estimating the project cost at completion.

Clearly the conditions of different projects are different from one to another, however it can even be argued that the conditions are different from one phase to another within the same project. In 
cases where the value of the activities is high, traditional approaches are not capable of providing reliable results. Therefore, a better index should be used in calculating the performance index and estimating cost at completion.

The models introduced in this study can be useful for project managers who have a strict limited budget by providing a more realistic estimation for the final cost. By using these methods in addition to professional analyses, project managers can prevent budget overruns and reduce costs in their projects.

Moreover, monitoring the cost and schedule of project performance is one of the main keys in successful projects. A better monitoring and analyzing method led project managers to have more knowledge about the project process. Combination of statistical control charts and traditional EVM or EDM provides more information about the problems and improvements in the project process which can help project managers to do correction actions and monitor the project process during the life of project. So, the objective of this research is to introduce a better way to control and monitor the schedule performance of projects by applying quality control charts to the duration-based index for schedule performance. Statistical analysis provides more precise information for understanding the actual progress of the project schedule. Indeed, project managers will be able to track the behavior of performance indices over time and take corrective action for variations which may cause problems in the future 


\section{CHAPTER 2 - RESEARCH MOTIVATION}

\subsection{Literature Review:}

The Earned Value (EV) is a leading technique in monitoring and analyzing project performance and project progress. With an increasing number of projects in areas of industry, construction, service etc., the methods and standards of EVM become more consequential. EVM is an integrated management of scope, cost and schedule which emphasizes the planning and integration of a program's technical performance, cost and schedule to support the program manager's decisions. Figure 1 represents earned value management (EVM) as an integrating tool.

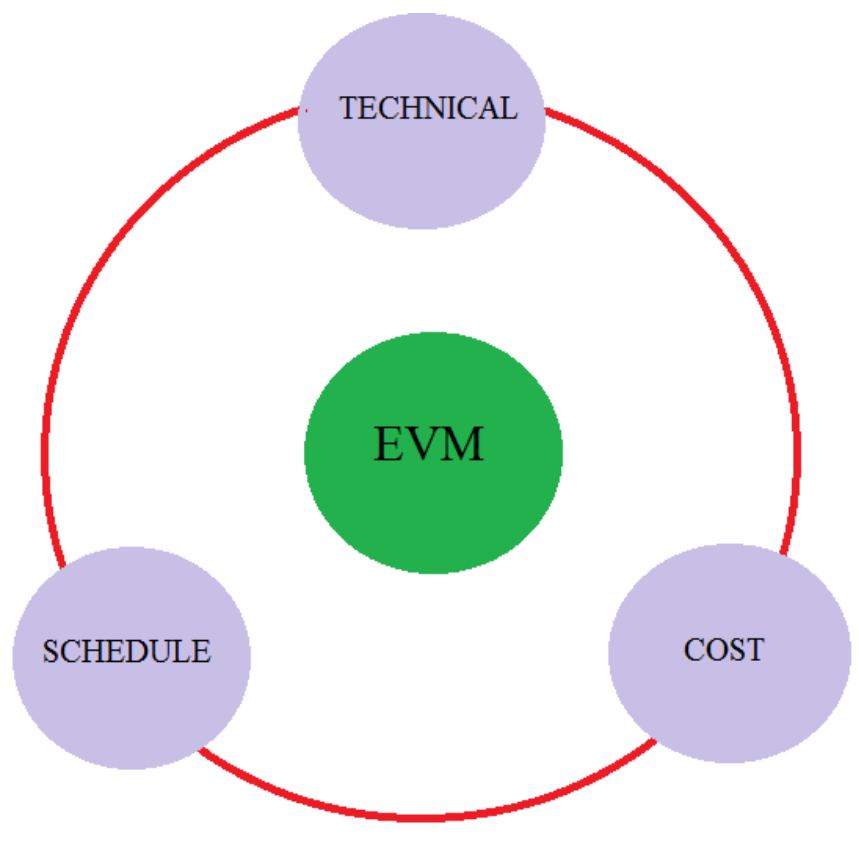

Figure 4. EVM as an integrating tool

$\mathrm{EV}$ is the measurement of what was physically received for what was actually spent, or the value of work accomplished. The concept of EV has gone by various titles, including "industrial factory standards," EVM, "performance measurement," and the "Cost/Schedule Control Systems Criteria (C/SCSC)". Regardless of all these terms, the main focus of EVM is on "the accurate measurement of 'work in progress' against a detailed plan to indicate what will happen to work on the project in the future" [19] 


\subsubsection{Evolution of Earned Value Management}

In 1958, the U.S. Navy first introduced the Program Evaluation and Review Technique (PERT) as a network-scheduling device for the Polaris Weapons System [14]. By 1962 PERT incorporated resources into its network analysis, thereby managing both time and cost [17]. Monitoring the cost performance of projects by using EV was the most important contribution from the PERT technique. In 1963 the U.S Air force used the EVM approach for their Minuteman Program [1]. The Air Force defined the 35 criteria as the minimum requirements of an acceptable project management system. Based on the need for new management techniques to build upon the PERT methods, the Department of Defense introduced an improved version of EVM which contained aspects of the C/SCSC, as well as the essential elements of EVM as practiced today [13]. To make EVM more user-friendly and compatible with the needs of private industry, the National Defense Industrial Association (NDIA) re-engineered the original 35 C/SCSC criteria into the Earned Value Management System (EVMS) criteria, which consisted of 32 straightforward guidelines [18].These are organized into the following five categories [33]:

- Organization: Activities that define the scope of the effort and assign responsibilities for the work.

- Planning and Budgeting: Activities for planning, scheduling, budgeting and authorizing the work.

- Accounting: Activities to accumulate the costs of work and the material needed to complete the work.

- Analysis: Activities to compare budgeted, performed and actual costs; analyze variances; and develop estimates of final costs.

- Revisions and Data Maintenance: Activities to incorporate internal and external changes to the scheduled, budgeted and authorized work.

In recent years, EVMS has become more popular in the domestic private sector and within the global community. Song (2010) explains the global adoption of EVM as follows:

"The U.S. has played the leading role in formalizing and disseminating EVM knowledge and applying EVM to a wide variety of industries. Many industrialized nations, such as Australia, 
Canada, Sweden, and the U.K., as well as some fast-growing economies in Asia and the Middle East have also followed suit and adopted EVM in their industries."

The Project Management Institute's $\left(\mathrm{PMI}^{\circledR}\right)$ A Guide to the Project Management Body of Knowledge $\left(\mathrm{PMBOK}^{\circledR}\right.$ Guide) provides the basic terminology and formulas of EVM. The terminology was simplified, and more details on EVM were provided starting in 2000 and in subsequent editions of the $\mathrm{PMBOK}^{\circledR}$ Guide (PMI 2008). This information was also included in a separate Practice Standard (PMI 2005b). Table 1 shows the EVM progress timeline.

Table 3. EVM progress Timeline [33]

\begin{tabular}{|l|l|}
\hline Year & \multicolumn{1}{|c|}{ Event } \\
\hline 1967 & $\begin{array}{l}\text { Cost/Schedule Control System Criteria (C/SCSC) introduced by U.S. } \\
\text { Department of Defense (DOD). }\end{array}$ \\
\hline 1972 & $\begin{array}{l}\text { First C/SCSC Joint Implementation Guide issued to ensure consistency among } \\
\text { military departments. }\end{array}$ \\
\hline 1991 & $\begin{array}{l}\text { DOD Instruction 5000.2-Defense Acquisition Management Policies and } \\
\text { Procedures issued reaffirming use of EVM. }\end{array}$ \\
\hline 1996 & $\begin{array}{l}\text { DODR 5000.2-R-Mandatory Procedures for Major Defense Acquisition } \\
\text { issued. Draft industry guidelines accepted by Under Secretary of Defense and } \\
\text { C/SCSC revised from 35 to 32 criteria }\end{array}$ \\
\hline 1998 & $\begin{array}{l}\text { American National Standards Institute / Electronic Industries Alliance } \\
\text { published industry guidelines for EVM Systems (EVMS; ANSI/EIA-748-98). }\end{array}$ \\
\hline 2000 & \begin{tabular}{l} 
Under Secretary of Defense adopts ANSI/EIA-748-98 for DOD acquisition. \\
\hline 2005
\end{tabular} \\
\hline
\end{tabular}

\subsubsection{Review on cost and schedule performance in EVM:}

One of the significant uses of Earned Value EVM is measuring the cost and schedule performance of projects. These measurements can be used in forecasting the final cost and budget, and in calculating the progress of projects; hence, it is to the advantage of project 
managers to try to improve these indices in order to have a better calculation for the progress of their projects.

Fleming and Koppelman (2003) provide an overview for EVM's use for cost control and forecasting. In that study the CPI and its application for forecasting is defined. The article also mentions Computer Sciences Corporation by name as a successful adopter of EVM, lending some initial credence to future research based on CSC's historical project data.

Anbari (2003) provides an excellent overview of EV application, covering the fundamentals of cost and schedule calculation, performance indices, completion forecasting methods for budget and schedule and recommendations on how to quantify management by exception and expected responses to project variances. In that paper he noted that "EVM has not been widely used to estimate the total time at completion, total project duration, or schedule for an activity, work package, or project based on actual performance up to a given point in the project." By adding the actual time, and a derived time estimate to completion (TETC) the forecasts are calculated.

Lipke (2003) presents an introduction of Earned Schedule (ES) and explains the limitations of EVM in measuring and predicting project schedules. In EVM the schedule performance index is calculated from the difference between the earned value (Budgeted Cost of Work Performed) and planned value (Budgeted Cost of Work Scheduled), even though these two values should converge at the end of a project. This means that it is not possible to find the delay until the end of the project. ES is the concept that Lipke (2003) used to solve this issue. In ES, the difference between the point in time at which a given Budgeted Cost of Work Performed is accomplished and the point on the Budgeted Cost of Work Scheduled should have been accomplished is the basis for the new schedule performance index. He illustrates the superiority of his method by using two different projects, one of which was on time and the other of which had delays.

Henderson (2005) expanded upon the previous study of ES. He provided some steps in the evolution of ES by using this methodology on real-world projects and showed that the combination of EVM and ES contributes a method which can be easily applied to a wide range of projects.

Jacob and Kane (2004) indicated that the schedule performance indices such as SPI and SPI(t) can have accurate results only when they are used on activity level not on the higher WBS levels. 
However, Vanhoucke (2011) noted that the accuracy of measuring the project performance on high WBS levels is acceptable because the project network is actually a serial structure which has many critical activities. Moreover, for solving this issue Diang and Zhang (2006) introduced a parameter to measure the criticality of each activity based on their limited float and thereby developed a weighted SPI.

Book (2006) presents an algebraic problem with the ES calculations and metrics. He noted that, in calculating the ES, one part of it is in units of time while the second part is without units, so it is an algebraic contradiction and results in a meaningless quantity. In the same year Jacob (2006) mentioned this same problem with the units of ES. He then added that if the part of ES which is unitless is multiplied by a single time period, all components will be then have the same units and the problem will be solved. He applied his proposed solution to three different project scenarios: very late, late and ahead of schedule.

Valle and Soares (2006) identified the main benefits of EVM, which are that it contains i) integrated cost, progress and time management; ii) better vision of the project in terms of scope and procurement; iii) early alert to problems; iv) foreseeability of project deviation trends; v) reduced time to perceive and understand problems and solutions; vi) support for negotiations and the decision-making process; and vi) the motivation of people to implement the project control process.

Vitner (2006) proposed evaluating project performance in a multi-project environment by using the EVMS combined with Multidimensional Control System (MCS) methods.

Solomon and Young (2007) discussed performance-based EVM, which combines product quality requirements into traditional EVM and integrates technical performance along with cost and schedule performance.

\subsubsection{Final estimation and forecasting in EVM:}

Some researchers have proposed developments to the basic methods, mainly related to improving the forecasting ability of EVM. Henderson (2003) used the ES method in six completed projects, of which three were finished late and three were finished early, where the author notes that the ES calculations quantified the delay in terms of time. He also used ES to calculate the Independent Estimate of Duration (IED) and an Independent Estimate of 
Completion Date (IECD). The main emphasis of this paper is the applicability of ES in providing more accurate calculations of schedule completion forecasts, mainly for IEAC and IED. Vanhouckel \& Vandevoorde (2007) indicated three methods of schedule performance monitoring and prediction: EV, ES and Earned Duration (ED). They used 3,100 simulated projects to test these three methods, and in each of them the Mont Carlo principles were used to create different scenarios (eg, behind schedule, ahead of schedule or on schedule). The calculation of the Mean Absolute Percentage of Error (MAPE) for each simulation scenario shows the accuracy of the methods. The results indicated that the ES method provides the best predictive performance. They conclude that "The results reveal that the ES method outperforms, on the average, all other forecasting methods. The closeness of a network to a serial or parallel network directly influences the activity slack and has an impact on the accuracy of the forecasts."

In order to have a more reliable forecasting method of final cost and duration Anbari (2009) applied some statistical methods to EVM. His sample data was taken from 12 high-technology projects with five different scenarios. In this paper he focused on analyzing the reliablility of the prediction for cost and schedule.

With regards to the evolution of the EAC, De Marco (2009) used nonlinear S-curves and considered the specific behavior of a project schedule.

Byung-cheol and Reinscgmidt (2009) explained a probabilistic forecasting method based on Bayesian inference and the Beta Distribution.

Kim and Reinschmidt (2010) combined the Kalman filter and ES method in order to provide a better forecasting for project duration at completion.

In order to solve the uncertainty of projects Naeini (2011) introduced fuzzy-based EV indices and estimation. She analyzed and controlled the performance of projects under uncertainty conditions. In addition, Salari (2015) used the Fuzzy time series model to approach an effective estimation process. By using this method, project managers can receive an early warning for upcoming performance issues with a project.

\subsubsection{Statistical Methods in Earned Value Management:}

There is less available research in the application of statistical methods to enhance EVM. Lipke (2002) discussed the statistical distribution of several cost indices on EV, as well as a method for 
converting the non-normally distributed data to a normal distribution. Christencen et al. (2003) also studied the statistical distribution of cost data and showed how the data can be normally distributed. In order to determine the forecasted project estimates, Barraza et al. (2004) applied stochastic S-curves. He combined the probability of completion with actual performance on plan. Later, Steyn (2008) introduced another point of view for the quality of projects and studied framework for managing quality on several projects.

Lipke et al. (2009) then introduced a forecasting method for the final cost and duration of projects besides the confidence interval for this purpose. He showed the advantage of his method by applying it to 12 real projects. Vaughn (2000) monitored the EVM indices by using statistical quality control charts, but in this study he assumed that all the distributions were normal. Naeni et al. (2011) studied fuzzy control charts as a more realistic monitor on EVM indices. Leu and Lin (2008) used the individual control charts to monitor project performance; however, they did not verify the auto-correlation among the data. Aliverdi (2013) applied ImR charts for indices and used statistical hypothesis tests to verify the autocorrelation of data to overcome this limitation. However, he fails to consider a situation in which the measurements are dependent on each other and are not stationary.

\subsubsection{Considering financial factors in Earned Value Management}

Since the EVM determines the project performance for the future performance trend, it has been used in a wide range of business environments. Consideration of the financial aspects was also a point of interest to some researchers. Hwee (2003), Gorog (2009) and Maravas (2012) each considered EVM and cash flow separately. Deltek (2008) noted that the financial aspect is one important factor to projects, and that budget overrun causes projects not to accomplish their goals. In none of this research are EVM and financial aspects considered in a unique system. Bagherpour (2010) introduced a model that estimated the final budget of projects by considering the time value of money and delays in payment.

\subsubsection{Earned Duration Management}

Using cost for schedule performance provides inaccurate results for monitoring projects. Khamooshi (2014) introduced a way to decouple the cost and schedule dimensions, as well as several duration-based factors for calculating schedule performance. He represented the 
notations in two categories: Micro, or activity-level, and Macro, or project-level. He argued that, with such tools, project managers can more easily evaluate and monitor the project.

\subsubsection{Control Charts}

In the univariate statistical process control, there are several types of control charts for monitoring process characteristics. Shewhart charts, cumulative sum control chart (CUSUMcharts) and exponentially weighted moving average charts (EWMA charts) are the most significant control charts. The Shewhart [46] type of control charts divide the process variation into two types: chance causes, resulting from inevitable environment variation, and assignable causes, resulting from some human and machine error [46]. In 1959, Robert [47] proposed a control chart based on the exponentially weighted moving average (EWMA). The influence of past observations is determined by a smoothing parameter $\lambda \in[0,1]$. Healy [48] proposed CUSUM charts for monitoring the mean of a multivariate normal sample in 1987. All of these attempts were derived under the assumption that the observations are independent. Alwan and Robert [49] mentioned that this condition is very restricted, and it cannot be fulfilled in many applications. They showed that autocorrelation can significantly deteriorate the performance of control charts. Alwan [49] suggested monitoring residuals using Shewhart control charts, which they refer to as common cause charts (CCCs), and special cause charts (SCCs). The former is a chart of fitted values which shows the current level of the process, and the latter is the standard control chart for the residuals. The chart is based on the assumption that the residuals are random.

\subsection{Research Motivation}

Monitoring the performance of a project helps project managers to have better information about the project, so providing a better method for analyzing the cost and schedule performance of project would prevent or reduce spending on overrun and budget issues. Applying quality control charts is one of the methods which can help project managers to find the small cost and duration deviations from their plan. However, in some cases there is a correlation between the cost and schedule performance indices, which causes an issue in applying the traditional Shewart control charts. Such cases, which are common in real projects, require different control charts. By using the method introduced in the next chapter, even the variations of autocorrelated data can be monitored during the life of a project. 


\section{CHAPTER 3. METHODOLOGY}

\subsection{Limitation of Traditional Procedures}

One of the most critical problems that project managers encounter is the management of performance on their project, where two of the most common problems are cost and schedule overruns. Some unpredictable problems may occur during the duration of a project, but good planning can help managers to assuage these issues. Using EVM methods can help managers to determine the current status and to predict the future status of their projects. Nevertheless, in traditional approaches there remain some shortcomings which can lead to unreliable results. An overview of common deficiencies is as follows:

1. Considering cost-based parameters in measuring the schedule performance of projects

2. Lack of an accepted level of cost and time deviation from the plan

3. Lack of checking the dependency of measurements

4. Neglecting the time value of money and delays in payment in calculating the final cost

5. Considering the whole of the project as a monolithic unit

\subsection{Duration-Based Parameters in Measuring Project Schedule Performance}

Considering cost-based parameters in calculating the schedule performance of projects is one common mistake of traditional methods. In some scenarios where the value of the activities is high and there are schedule delays, the previous methods which calculate the schedule performance of projects by using cost-based parameters provide inappropriate results.

Overemphasizing cost, and using cost as the main proxy for measuring the schedule performance of projects, is the main reason behind hundreds of project failures. Decoupling the schedule and cost dimensions of projects is the key to creating a better schedule performance index. The Earned Duration Management (EDM) system is the method which is suggested in this paper. EDM emphasizes the duration/schedule aspect of the project, and provides some duration-based parameters that can be used to measure the project schedule performance. The new schedule performance indices in this method are EDI (Earned Duration Index) and DPI (Duration Performance Index). Therefore, it is suggested to use EDI and DPI as the schedule performance indices of a project. 


\subsection{Finding Cost and Time Deviations from Plan}

In practice, the performance indices are compared against one another and the deviations are reported. However, this process does not usually provide additional information about the variation allowed for each index. Therefore, having some additional information about the measurement indices is of interest. In fact, comparing the performance indices against one another can show if a project is ahead of budget, behind the budget or on the planned budget. A CPI of 1 shows that everything is under control; however, even small deviations may still contain warnings about the current or future status of a project which may require corrective actions. Moreover, in a high-priority project, small variations from the plan may be very important, so they must be distinguishable. The traditional approach for evaluating and monitoring project progress is not capable of detecting such small variations. The target of this study is to improve the monitoring of project performance. Applying statistical quality control charts to the project performance indices can also monitor the performance and progress variations, allowing even small variation to be tracked.

Combing the Earned Duration System, Earned Value system and statistical quality control charts may improve the capability of traditional systems. Indeed, this combination can help to find important changes in the project time and cost progress. This approach reveals more information for evaluating and analyzing the project performances.

\subsubsection{Statistical Process Control Charts}

Statistical process control (SPC) is a branch of statistics which is used to monitor and control a process. Applying SPC helps managers to detect changes in a process over time and identify important factors affecting the process. Variations are inescapable in every process. Some examples are common cause variations, which are intrinsic to the process, and are called control variations. The other group is called uncontrolled variations, which are not innate to the process, so each has a particular cause. If the process variations include both common and special causes of variation, the process is said to be out of control. SPC is used to detect the presence of special causes of variation. Many types of SPC exist for controlling processes, but SPC charts are the most operational method among them.

The basic fundamentals of SPC and control charts were proposed by Shewhart in the 1920's. Although some other researchers tried to improve the control charts, Shewhart's is still the most 
useful. Individual control charts are reserved for situations where only one measurement is performed each time the data is collected. Therefore, it is suggested to use this kind of chart as the special cause control charts in this study. The first assumption that must be made when using individual control charts is normality of the measurements. If the distribution of measurements is not normal, the transformation should be used to convert them to normal.

The second assumption for using Shewhart control charts is independency of the measurements. For variables that have normal distribution, independence is equivalent to non-correlation, so calculating autocorrelation to verify the independency of measurements from their own past and future values is suggested. In fact, autocorrelation is used to refer to lack of independency among the values of measurements at different points of time.

Calculating the autocorrelation of measurements can show their dependency. Many times in industrial practices, especially in continuous production processes, observations are not independent. Under such conditions, traditional SPC charts may be inappropriate for monitoring process quality. Alwan and Robert [49] proposed an approach to the problem of data correlation. In this approach the process should be modeled by ARIMA models to obtain the process residuals. When the modeling is completed SCCs, which is a standard control chart of the residuals, should be applied. Since the residuals are independent and identically distributed, all the assumptions of traditional quality control hold. In this study for monitoring the performance of project, it is suggested to use an ARIMA model for cost performance index (CPI) and schedule performance indices, which are EDI and DPI. Then the SCCs are applied on the residuals of their process models. Calculating the autocorrelation of these measurements, the lags of dependency can define the order of AR model. Moreover, the best ARIMA model can be found according to the stationarity of the data.

\subsubsection{Checking Normality of EDM Indices}

As control charts assume the normality of the measurements, it is essential to check the normality of the data, which are EDI and DPI in this paper. There are some statistical hypothesis tests for checking the normality of a set of data. Anderson- Darling is used in this research. The hypothesis normality test is:

$\left\{H_{0}=\right.$ Data follow a normal distribution $\left\{H_{1}=\right.$ Data do not follow a normal distribution 
If the p-value of each test is greater than $\alpha$ (level of significance), the null hypothesis will not be rejected; otherwise, it should be rejected. Indeed, if the p-value is a large number, such that it is greater than even larger values of $\alpha$, we should not reject $H_{0}$, which is that the distribution is most likely normal. In the case that $H_{0}$ is rejected, it means that the distribution is not normal and the transformation should be used to convert them to normal distribution.

Because the Johnson transformation can successfully be applied on both positive and negative data in this study, this transformation is used. The Johnson transformation function is selected from a family of distributions which are as follows:

$$
\widetilde{X}= \begin{cases}\frac{(x+1)^{\lambda}-1}{\lambda} & \text { if } \lambda \neq 0, x \geq 0 \\ \log (x+1) & \text { if } \lambda=0, x \geq 0 \\ -\frac{\left[(-x+1)^{2-\lambda}-1\right]}{(2-\lambda)} & \text { if } \lambda \neq 2, x<0 \\ -\log (-x+1) & \text { if } \lambda=2, x<0\end{cases}
$$

\subsubsection{Checking Stationarity of EDM Indices}

A time series is stationary if its underlying statistical structure does not change with time.

Consider the mean of the series, which is determined by the underlying statistical structure of the series. Stationary implies that the mean must not depend on time.

A time series model is strictly stationary if the joint statistical distribution of $X_{t 1}, X_{t 2}, \ldots, X_{t n}$ is the same as the joint distribution of $X_{t 1+m}, X_{t 2+m}, \ldots, X_{t n+m}$ for all $t_{1}, \ldots, t_{n}+m$. Indeed, the distribution is unchanged after an arbitrary time shift. It can be shown as below:

$$
\left(X_{t 1}, X_{t 2}, \ldots, X_{t n}\right) \triangleq\left(X_{t 1+m}, X_{t 2+m}, \ldots, X_{t n+m}\right)
$$

Where $\triangleq$ denotes equality in distribution. In first order stationarity, the mean and variance are constant and the autocovariance $\operatorname{Cov}\left(X_{t}, X_{S}\right)$ only depends on lag $\mathrm{k}$. If the time series is not strictly stationary but the mean and variance are constant and the autocovariance only depends on the lag, then it is called second-order stationary. 
The time series plot can show the stationarity of data. If the data is not stationary, the differencing method can be used to convert it to stationary. Differencing the series converts each element $\mathrm{i}$ of the series into its difference from the element (i-k).

$Y_{t} \leftarrow Y_{t-k}-Y_{t}$

\subsubsection{Checking Autocorrelation of EDM Indices}

A useful plot to understand a process is the autocorrelation function. The autocorrelation furcation (ACF) of a series gives the correlation between $X_{t}$ and $X_{t+k}$. Theoretically, the autocorrelation at lag k refers to the correlation between $X_{t}$ and $X_{t+k}$ and is defined as:

$$
\rho_{k}=\frac{\operatorname{Cov}\left(X_{t}, X_{t+k}\right)}{\sqrt{\operatorname{Var}\left(X_{t}\right) * \operatorname{Var}\left(X_{t+k}\right)}}
$$

In a stationary process, it can be said that the autocorrelation for any particular lag is the same regardless of where one is in time. The first thing to do is to decide what order of an AR model will be used to build. By using a partial autocorrelation function (PACF) plot, the order of AR model can be found. From the lag of ACF and PACF, the best ARIMA model can then be found.

If the ARIMA models are fitted to the project cost and schedule performance indices, their residuals can be easily obtained, and applying special cause control charts on these residuals is suggested in this study.

In the next chapter the introduced method is applied to a real construction project so as to show the advantages of this method.

\subsection{Estimating the Project Final Cost}

Several studies have been done on estimating the final budget of projects. In this study, it is attempted to introduce a better method which produces more realistic results. Considering a monetary-based schedule performance index may lead to some misleading results, because schedule and cost are different dimensions of projects. Therefore, having a more accurate schedule index should be calculated based on duration. Hence the EDM's schedule performance is used instead of SPI, as in traditional methods. Moreover, delays in payment, cash flow and the time value of money are some financial aspects which have significant impacts on estimating the 
final budget of projects. By considering the financial aspects when estimating, the results are more realistic at completion. In addition, different phases of construction projects have various conditions, and considering them as a unified system causes project managers to analyze the projects erroneously. Assigning diverse weights to schedule, cost and financial factors for different phases of a project helps managers to produce a more accurate estimation of the final budget.

Equation 6 shows the EAC formula, which considers the project as a whole. However, each project includes various activities and phases which may have different circumstances. For instance, consider a civil project with three main phases: funding, skeleton, and installation. Different phases have different effects on the progress of the project. For considering the effect of each phase separately, it is suggested to allocate a distinct weight to the cost and schedule performance index of each phase. The sum of all weights allocated to performance indices should be equal to 1 .

For considering the time value of money and delay in payments in estimating the final cost, equation 16 is suggested by Bagherpour. In this equation, the index which is used for project schedule performance is SPI, despite the fact that EDI has been shown to be a better schedule performance index. EDI is a measure of duration compared to what was planned to be done up to the point in time when it is calculated. DPI is measured on the time axis, whereas EDI is an overall schedule/duration performance measure. Therefore, it is suggested to use EDI as the schedule performance index in estimating the final cost. Equation 20 shows a new formula for estimating the final cost.

$$
\begin{gathered}
E A C_{n e w}=\sum_{i=1}^{n}\left(A C_{i}+\frac{B A C_{i}-E V_{i}}{W_{1} * C P I_{i}+W_{2} * E D I_{i}+W_{3} * F P I_{i}}\right. \\
\left.+\frac{\left(E V_{i}-E M_{i}\right) *(1+i)^{D}-\left(E V_{i}-E M_{i}\right)}{F P I_{i}}\right)
\end{gathered}
$$

In this equation $\mathrm{n}$ is the number of main phases, $\mathrm{D}$ is the time delay in cash payment and $\mathrm{i}$ is the interest rate over the same time frame in which $\mathrm{D}$ is expressed. The amount of money that the employer has not paid is equal to $(E V-E M)$, and $(E V-E M)^{*}(1+i)^{D}$ represents the time value of this money. Therefore, subtracting $(E V-E M)$ from $(E V-E M)^{*}(1+i)^{\mathrm{D}}$ produces the extra money that should be paid by the employer for the delay. 
In the next chapter there is a comparison between this method and previous ones. All of these methods are applied to a real construction project in Iran, and the final estimates are compared. 


\section{CHAPTER 4. DATA AND RESULTS}

\subsection{Applying Residual Control Charts for Monitoring Project Cost and Schedule}

Monitoring the performance of a project can determine the failure or success of the project, so finding a better approach for monitoring and analyzing the performance of projects is of interest to many researchers. In traditional EVM, monitoring the project is based on Cost variance (CV) and schedule variance (SV), or CPI and Schedule performance index (SPI). However, this traditional method cannot provide information about variation in individual performance values. Using the SPC method can provide a more effective analysis which uncovers the accepted level of variations from cost and schedule targets.

Data for the performance evaluation in this study were taken from a real construction project. Appendix 1 shows the real data.

First, the normality of the EDM indices should be checked. The main software used for the statistical analysis was Minitab® version 17. Figure 5 demonstrates the normality of the EDI. The EDI is most likely normally distributed, primarily because its p-value is greater than the assumed level of significance, such as (0.2, 0.5). However, Figures 6 and 7 show that the small p-values of the DPI and CPI led to a rejection of the null hypothesis, so they most likely are not normally distributed. 


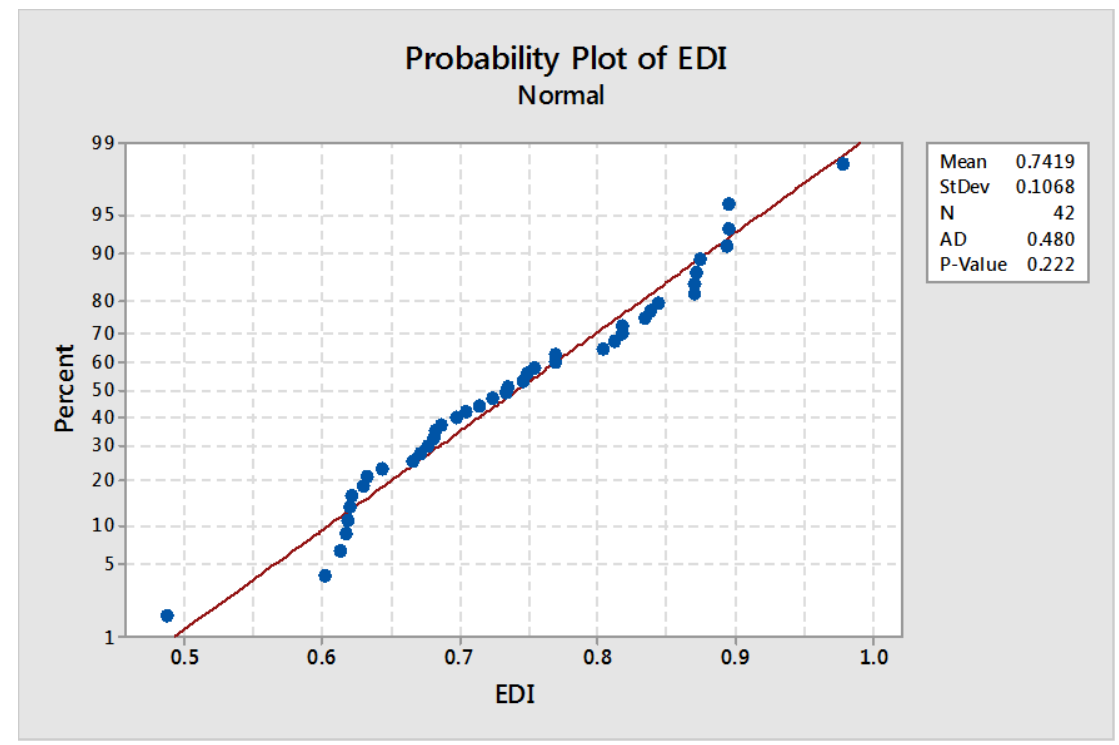

Figure 5. checking normality of EDI

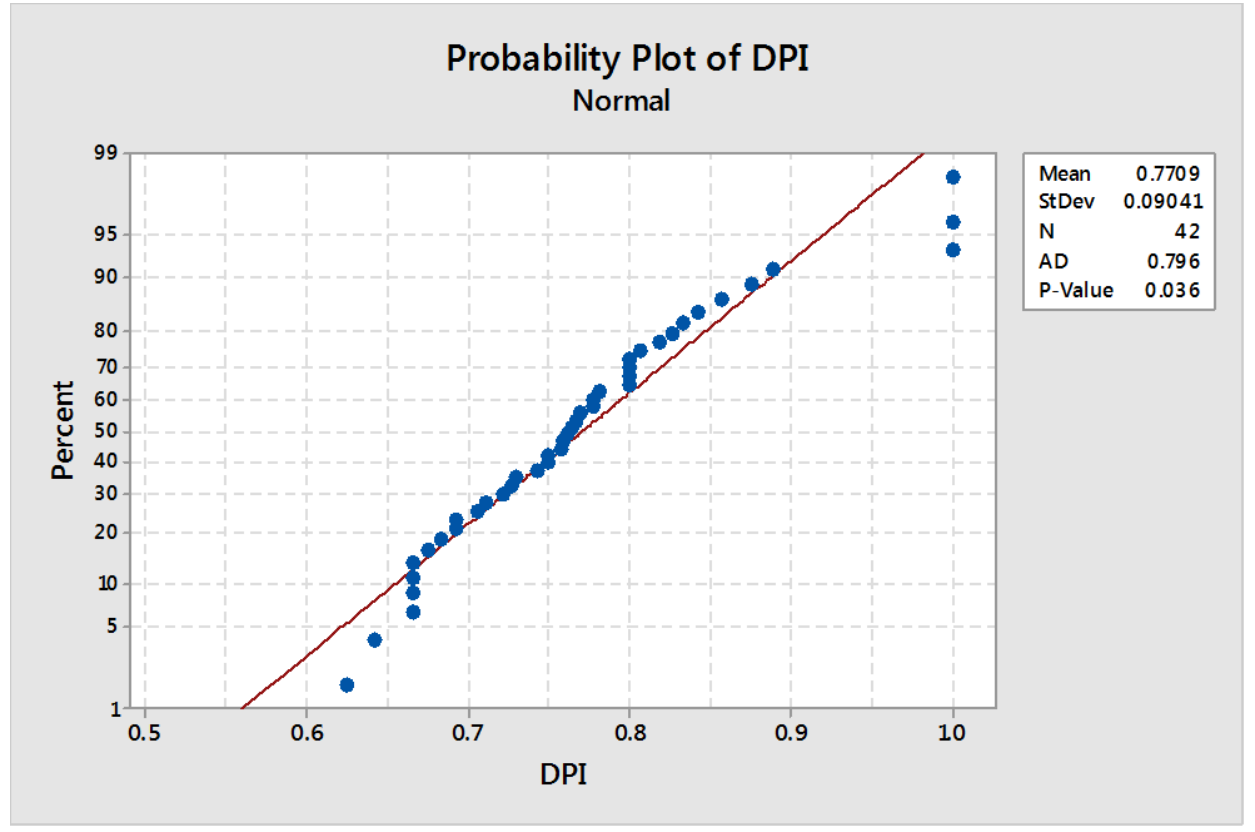

Figure 6. Checking normality of DPI 


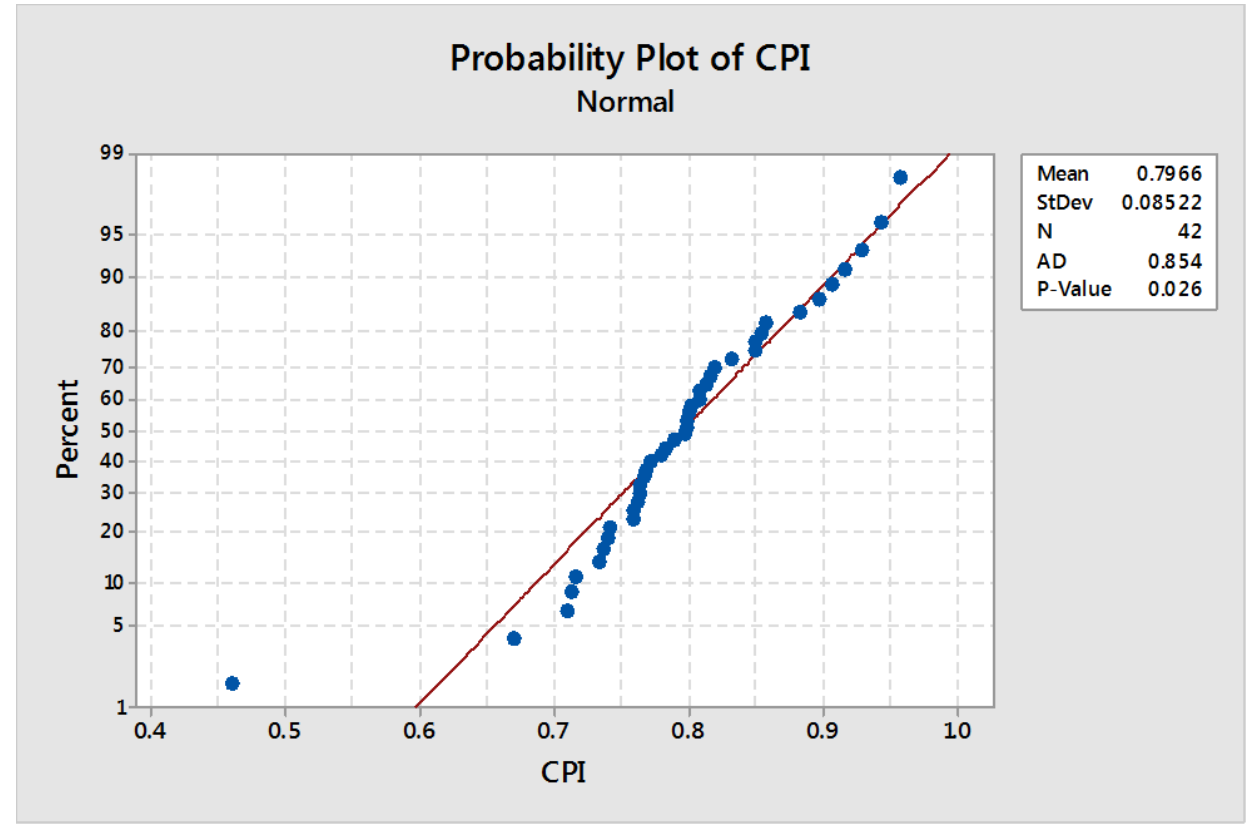

Figure 7. Checking normality of CPI

Applying control charts on the non-normal distributed set of data causes inaccurate results, so the set of data that do not follow the normal distribution needs to be transformed. Minitab® was used to transform the original DPI data to normally distributed data. Appendix 1 shows the summary of Johnson transformation on the CPI and DPI data.

The next step is checking the stationarity of the EDM indices. The time series plot shows the stationarity of data. Since the EDI, DPI and CPI are non-stationary, differencing was used to convert to stationary data. Figures 8, 9 and 10 show the time series plots of EDI, DPI and CPI, respectively, and their plots after the differencing of one lag.
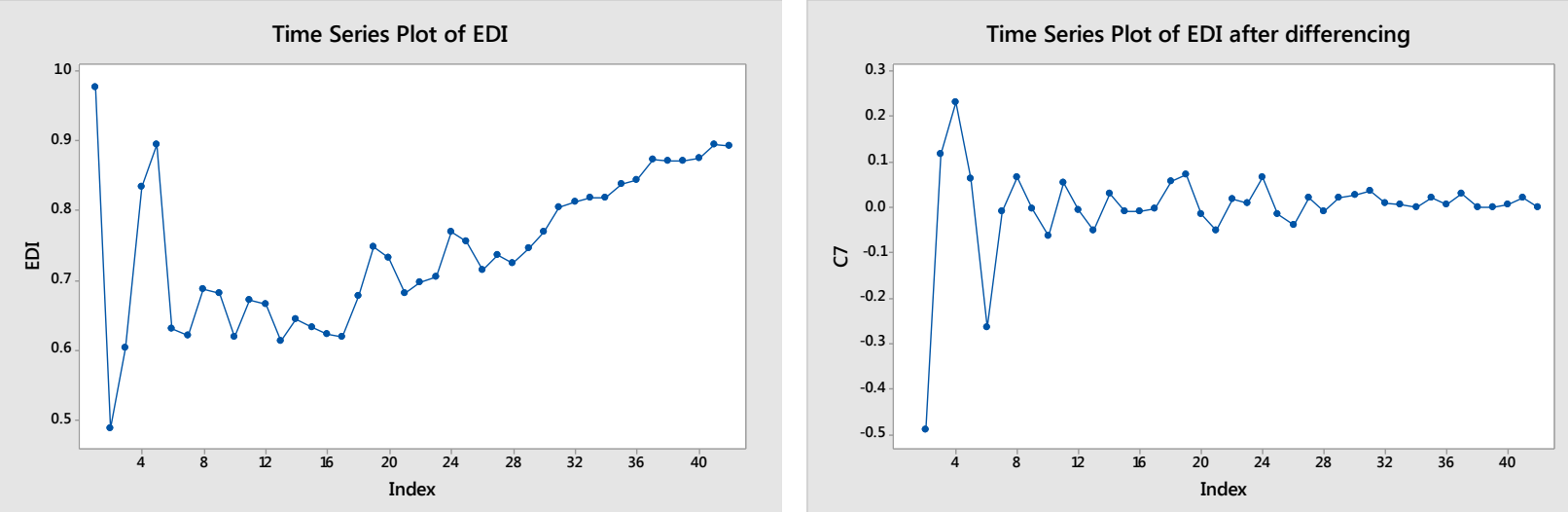

Figure 8. Time series plot for EDI before and after one lag differencing 

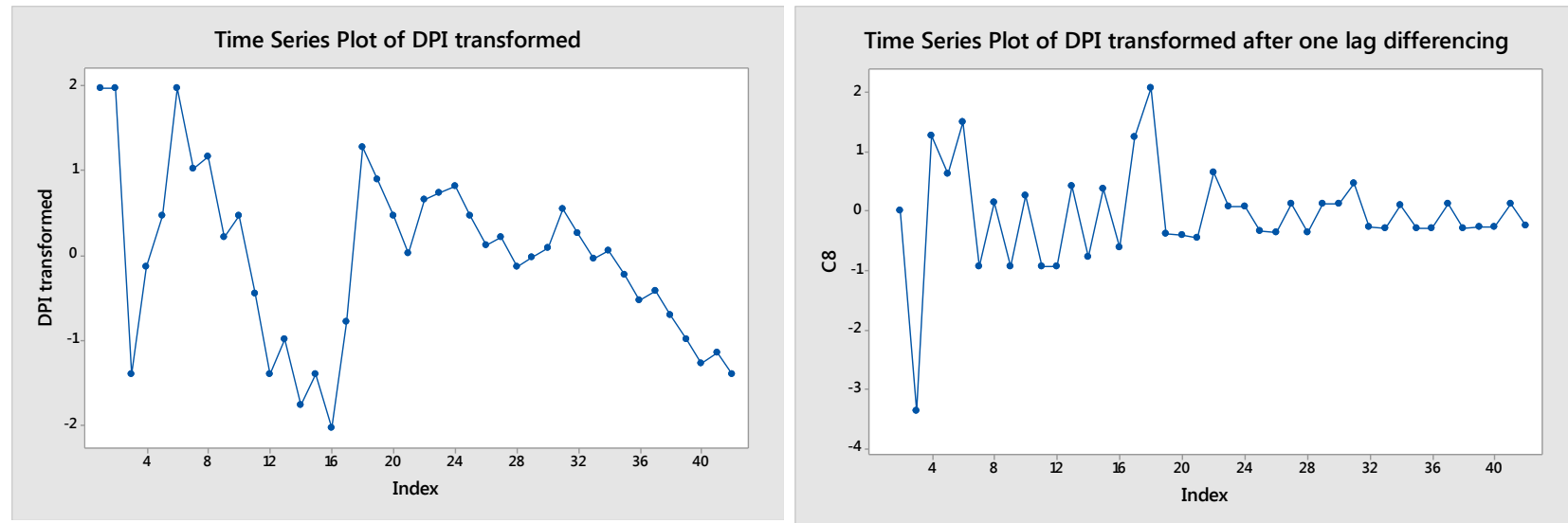

Figure 9. Time series plot for DPI transformed before and after one lag differencing
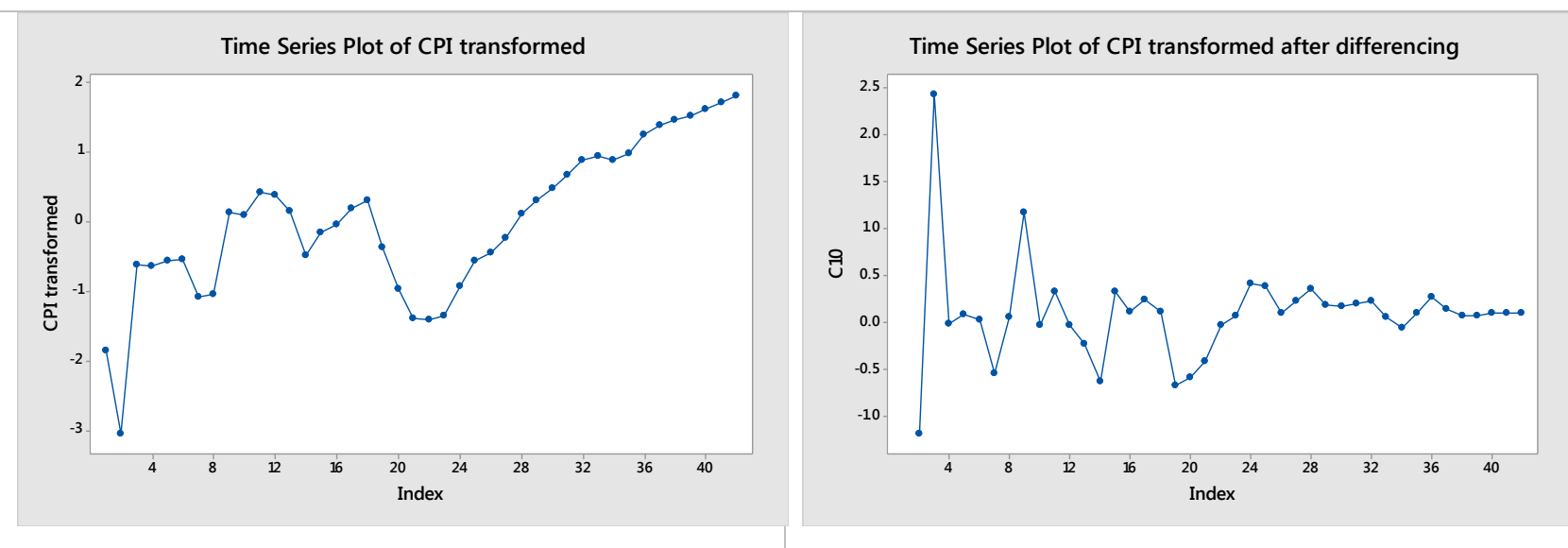

Figure 10. Time series plot for CPI transformed before and after one lag differencing

For checking the correlation of EDI, DPI and CPI, the autocorrelation function and partial autocorrelation function were used.

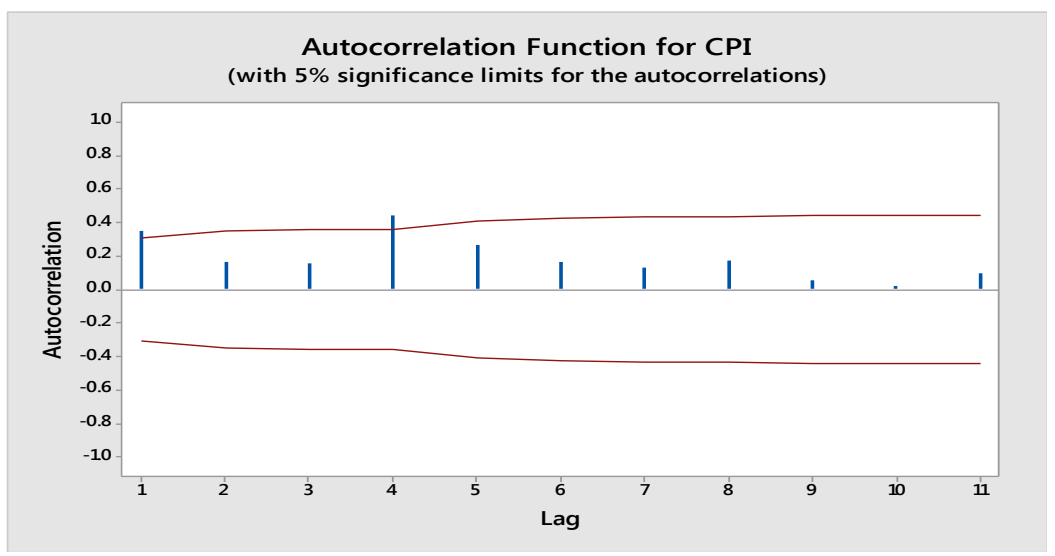

Figure 11. Autocorrelation of CPI 


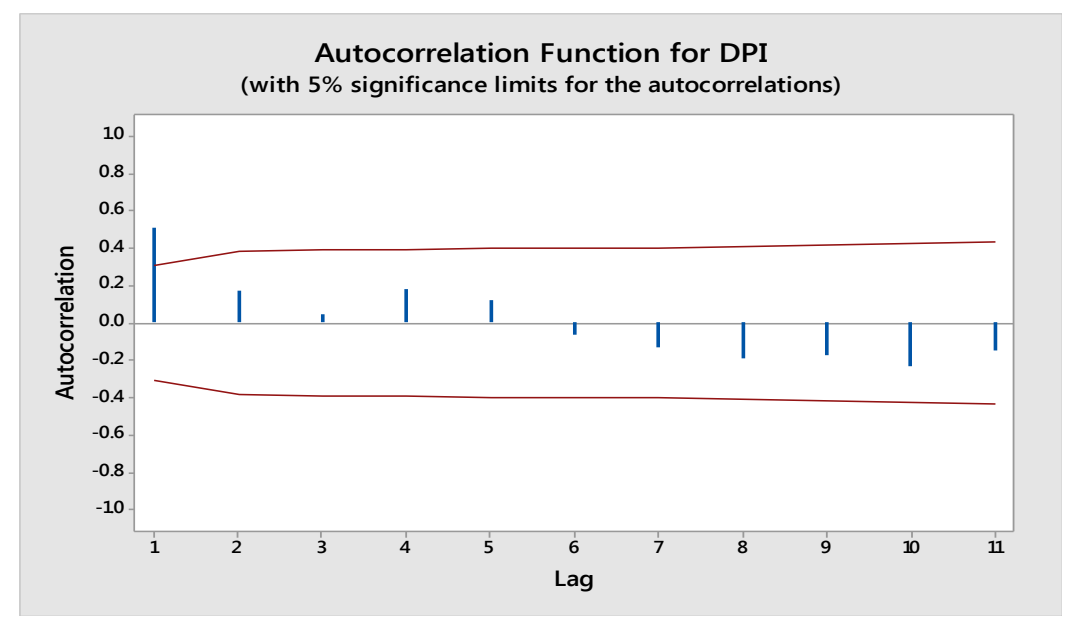

Figure 12. Autocorrelation of DPI

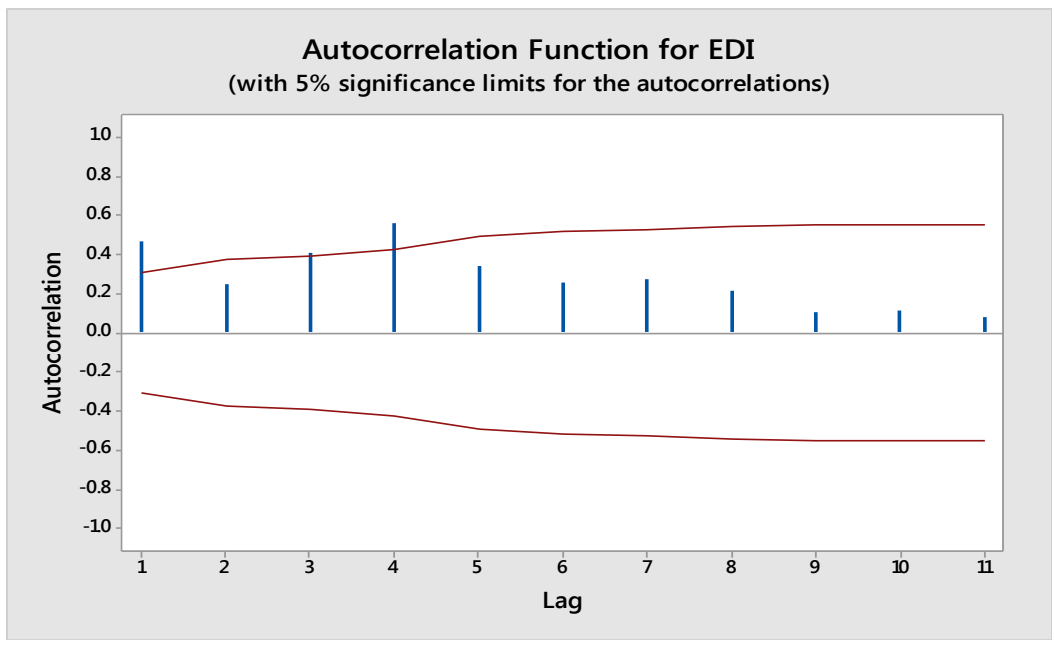

Figure 13. Autocorrelation of EDI 


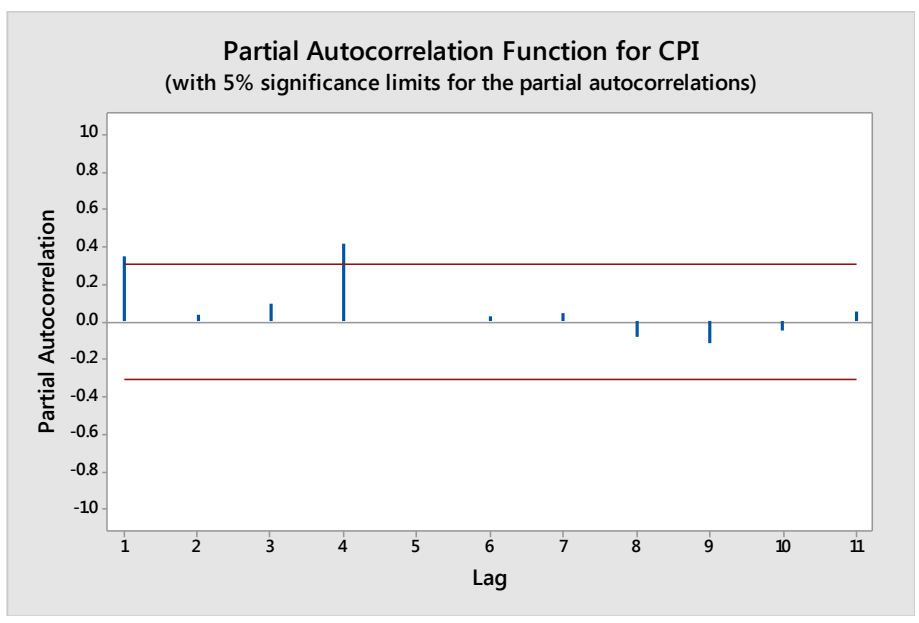

Figure 14. Partial Autocorrelation function of CPI

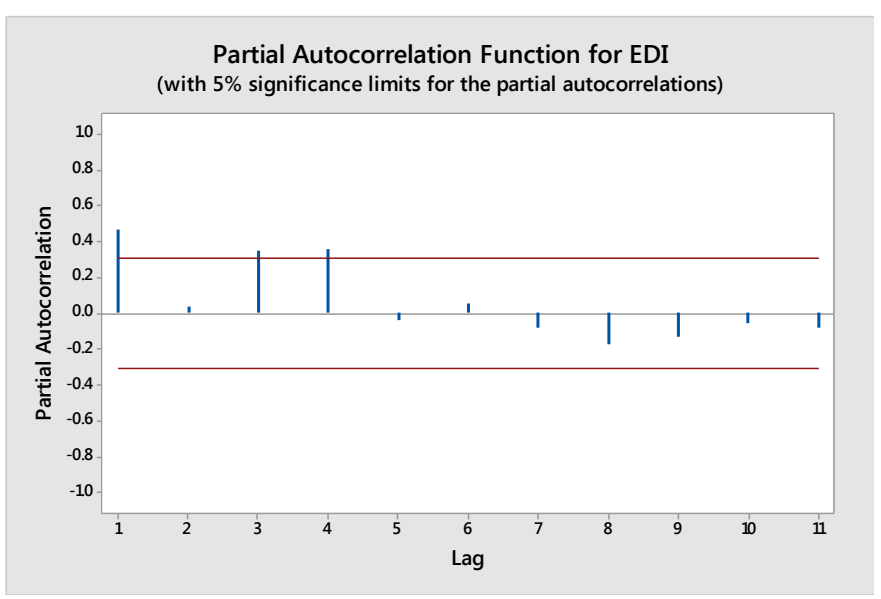

Figure 15. Partial Autocorrelation function of EDI

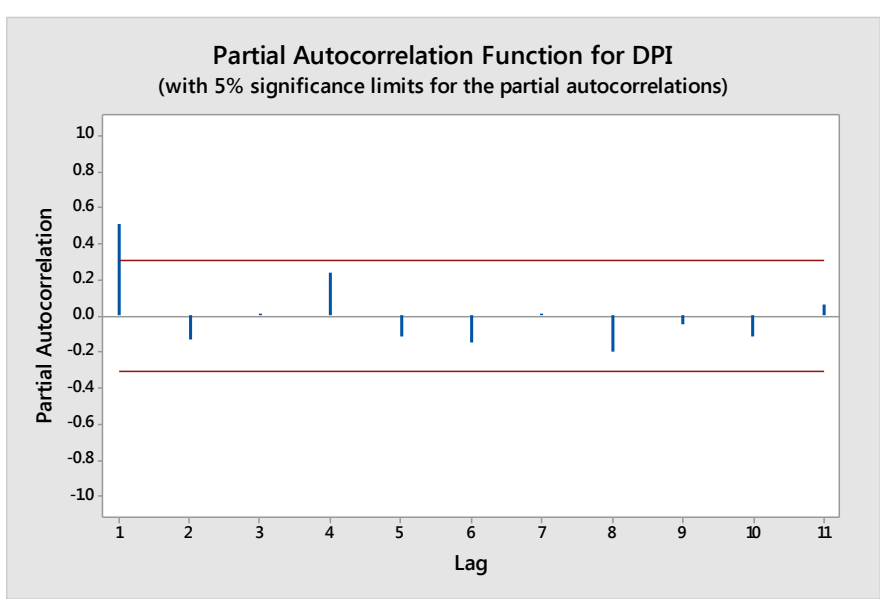

Figure 16. Partial Autocorrelation function of DPI 
According to this figure, it can be seen that for DPI the $1^{\text {st }}$ order autoregression model, denoted as $\mathrm{AR}(1)$, is the best, since there is only one significant spike at lag 1 . In this model, each value of $\mathrm{X}$ at time $\mathrm{t}$ is a linear function of $\mathrm{X}$ at time (t-1). Based on Figure 8 there are two significant spikes for CPI, so either the AR(1) or AR(4) should be selected. Moreover, Figure 9 shows three significant spikes for EDI, which are at lag 1,3 and 4. Thus AR(1), AR(3) and AR(4) are the options for building the model. Based on the table 5 , which is a pattern for identifying the order of ARIMA model, For DPI it is suggested to use the ARIMA $(1,1,1)$. Moreover, it is suggested to use $\operatorname{ARIMA}(4,1,1)$ for CPI, and EDI. 
Table 4 Characteristics of theoretical ACF and PACF for process. [52].

\begin{tabular}{|l|l|l|}
\hline Process & ACF & PACF \\
\hline AR(p) & $\begin{array}{l}\text { Tails off as exponential decay } \\
\text { or damped since wave }\end{array}$ & Cuts off after lag $p$ \\
\hline MA(q) & Cuts off after lag $q$ & $\begin{array}{l}\text { Tails off as exponential decay } \\
\text { or damped since wave }\end{array}$ \\
\hline ARMA(p,q) & Tails off after lag $(\mathbf{q}-\mathbf{p})$ & Tails off after lag (q-p) \\
\hline
\end{tabular}

Minitab 17 was used to fit the ARIMA models on the CPI, DPI and EDI indices. Tables 3, 4, and 5 show the parameters of the ARIMA model for CPI, DPI and EDI. Appendix 2 shows the residuals of the ARIMA model for CPI, DPI and EDI.

Table 5. ARIMA parameters for DPI

\begin{tabular}{|lrrrrr|}
\hline Type & & Coef & SE Coef & T & P \\
AR & 1 & -0.0041 & 0.1794 & -0.02 & 0.982 \\
MA 1 & 0.7944 & 0.1118 & 7.11 & 0.000 \\
Constant & 0.004226 & 0.002629 & 1.61 & 0.116 \\
\hline
\end{tabular}

Table 6 ARIMA parmeters for EDI

\begin{tabular}{|lrrrrr|}
\hline \multicolumn{1}{l}{ Type } & & Coef & SE Coef & T & P \\
AR & 1 & -0.9791 & 0.3222 & -3.04 & 0.004 \\
AR & 2 & -0.9642 & 0.3014 & -3.20 & 0.003 \\
AR & 3 & -1.0532 & 0.2777 & -3.79 & 0.001 \\
AR & 4 & -0.0829 & 0.2877 & -0.29 & 0.775 \\
MA & 1 & -0.6364 & 0.2259 & -2.82 & 0.008 \\
Constant & 0.01341 & 0.01519 & 0.88 & 0.383 \\
\hline
\end{tabular}

Table 7. ARIMA parmeters for CPI

\begin{tabular}{|lrrrrr|}
\hline \multicolumn{1}{|l}{ Type } & & Coef & SE Coef & T & P \\
AR & 1 & -1.1969 & 0.2533 & -4.73 & 0.000 \\
AR & 2 & -0.1673 & 0.2599 & -0.64 & 0.524 \\
AR & 3 & -0.0607 & 0.2556 & -0.24 & 0.814 \\
AR & 4 & -0.0949 & 0.1898 & -0.50 & 0.620 \\
MA & 1 & -0.9436 & 0.1820 & -5.18 & 0.000 \\
Constant & 0.2394 & 0.1637 & 1.46 & 0.153 \\
\hline
\end{tabular}

\subsubsection{Special-Cause Chart on Residuals}

After the residuals of time-series models are calculated and tested for normality, the SCCs should be applied. If some points fall out of control limits, they are out of control points. The 
project managers should find the cause of these out-of-control points, and do the necessary corrective actions to prevent it from happening in the future. If these points are above the upper control limit (UCL), they show better performance and finding their causes would improve the project. If the points fall below the lower control limit (LCL), they show poor performance and detecting them helps the manager to solve the problem. Although the points falling above the UCL represent good performance, for the purpose of interpreting the control charts they are still out of control.

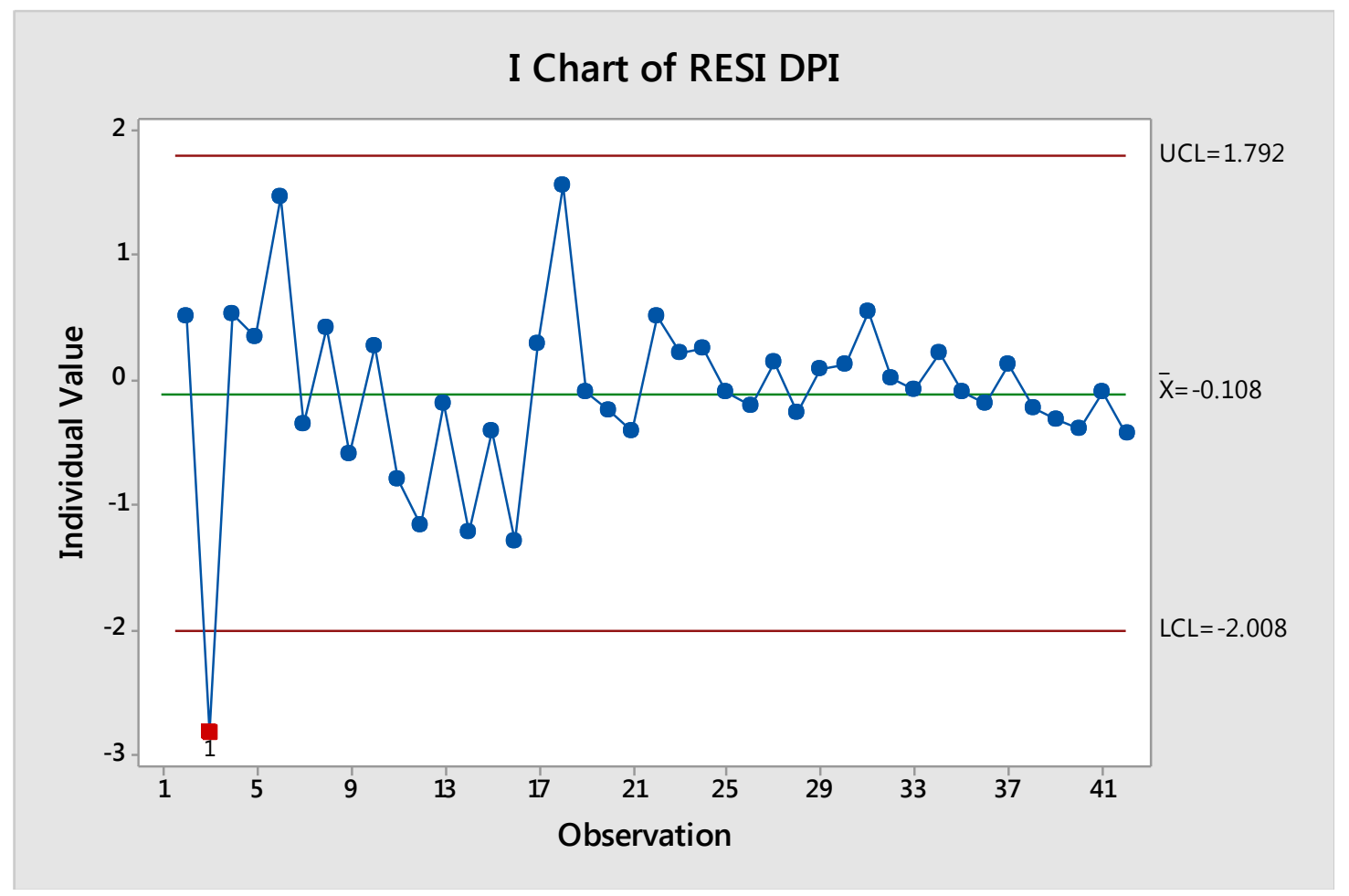

Figure 17. Special cause chart for DPI 


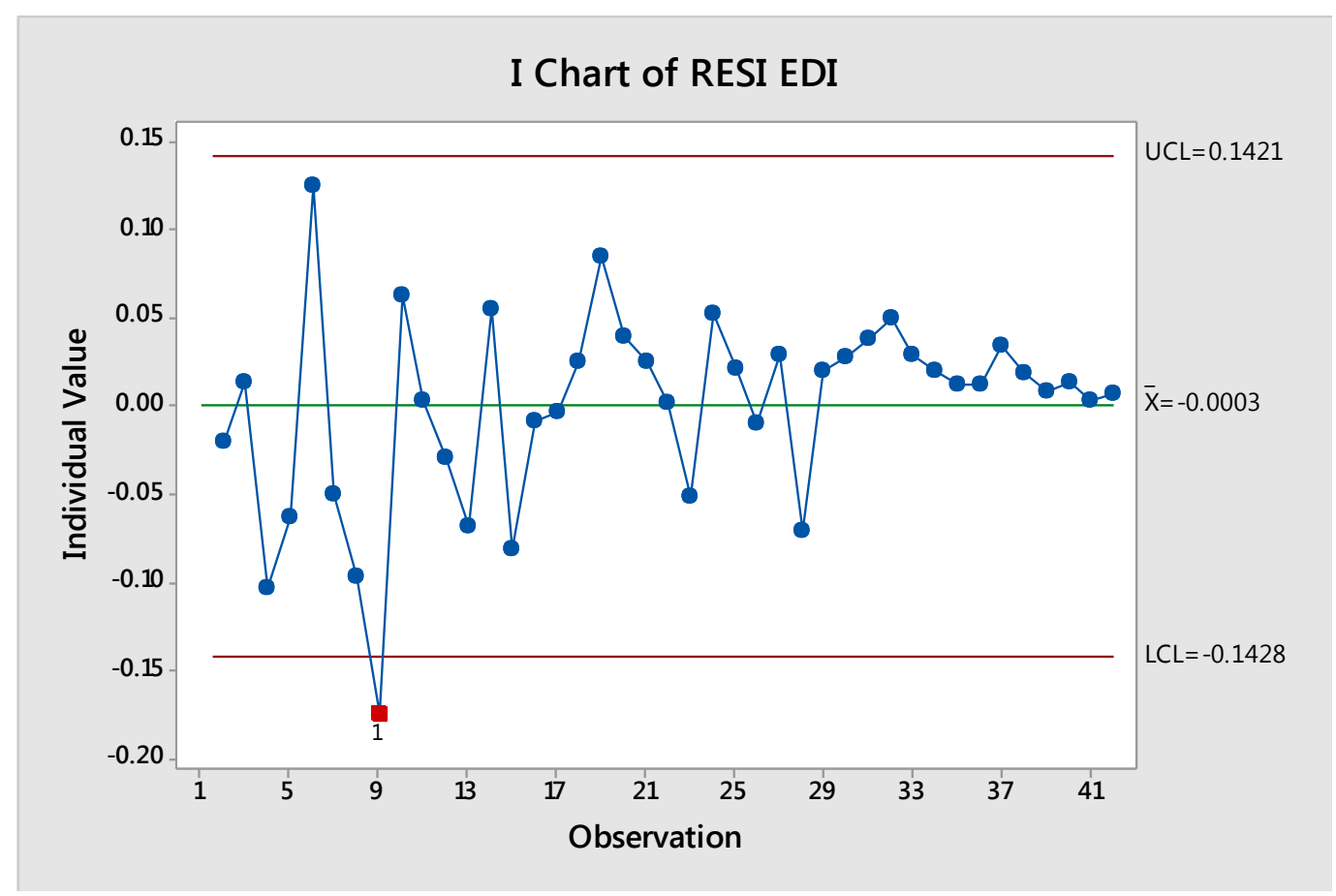

Figure 18. Special cause chart for EDI

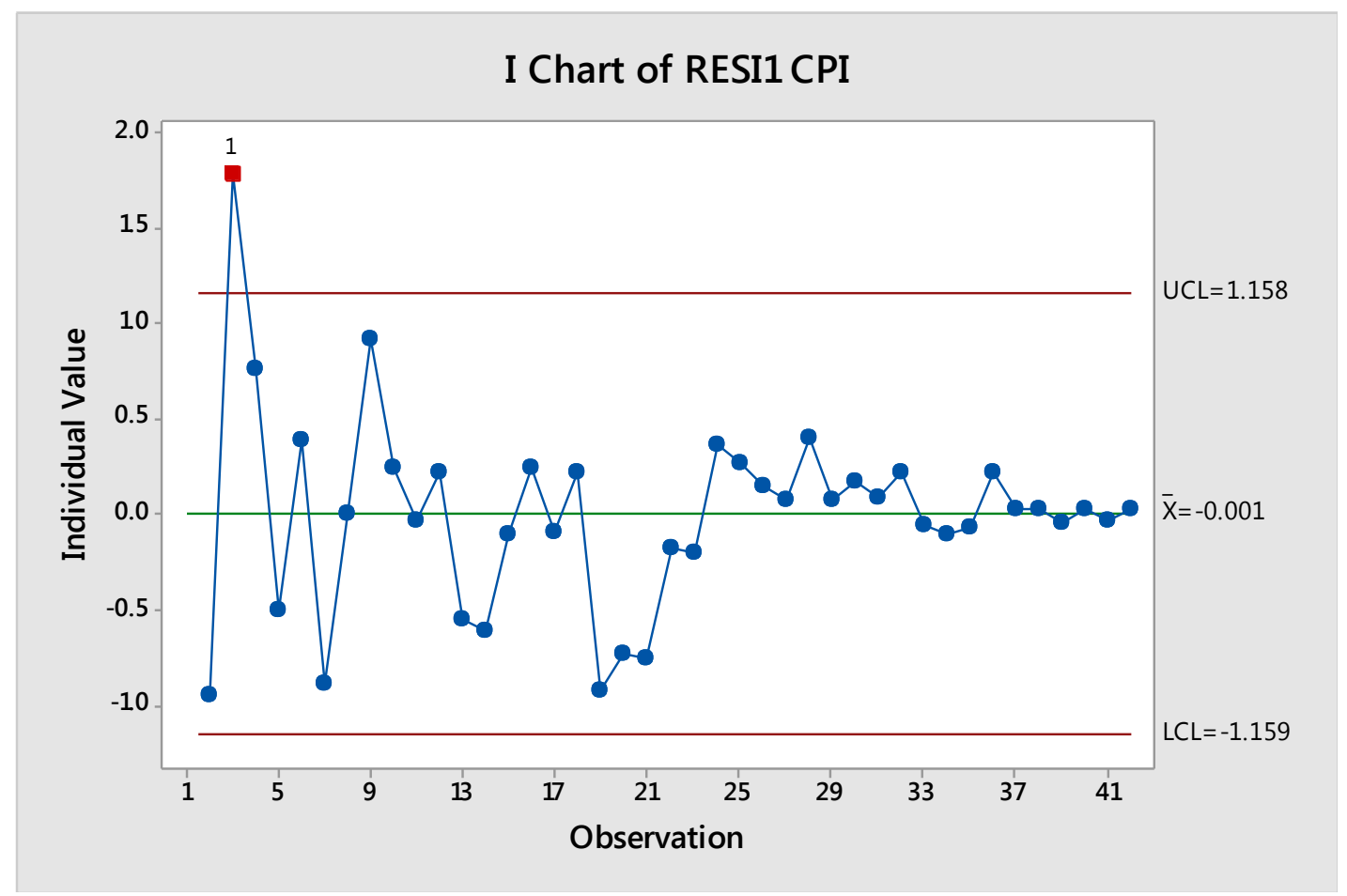

Figure 19. Special cause chart for CPI 
Analyzing the EDI and DPI provides information about schedule performance. As shown in Figure 17, one observation is out of the control limits. Since it is lower than the lower central limit, this means that something happened in the project process that caused a problem in schedule performance of the project. However, as shown in Table 8, according to the DPI the schedule is on-plan for weeks 1 and 2, and it is 0.7 for week 3, which is not a bad indicator. Based on Figure 18, one observation is out of the control limits; however, the traditional monitoring system shows that from weeks 6-10 the schedule performance is almost unchanged, indicating that there are no problems. However, based on the introduced method, the project team should check the checklist of project activities and find the cause of the problem in schedule performance. On the contrary, Figure 19 shows one observation above the upper control limits due to an improvement in the cost performance of the project. The cause of this improvement should be detected and repeated in the future to further improve cost performance. Finding the cause of problems and improvements in the project process gives project managers more information about the process of a project, which can prevent the problem from happening or ensure that the improvement happens in the future.

Table 8. The EDM indices for a construction project

\begin{tabular}{|c|c|c|c|}
\hline Week & EDI & DPI & CPI \\
\hline $\mathbf{1}$ & 0.977 & 1 & 0.67 \\
\hline $\mathbf{2}$ & 0.487 & 1 & 0.504 \\
\hline $\mathbf{3}$ & 0.602 & 0.7 & 0.760 \\
\hline $\mathbf{4}$ & 0.833 & 0.75 & 0.759 \\
\hline $\mathbf{5}$ & 0.894 & 0.8 & 0.763 \\
\hline $\mathbf{6}$ & 0.629 & 1 & 0.764 \\
\hline $\mathbf{7}$ & 0.619 & 0.857 & 0.733 \\
\hline $\mathbf{8}$ & 0.686 & 0.875 & 0.736 \\
\hline $\mathbf{9}$ & 0.681 & 0.777 & 0.799 \\
\hline $\mathbf{1 0}$ & 0.617 & 0.8 & 0.797 \\
\hline
\end{tabular}

Moreover, one of the ways for checking the accuracy of a method is calculating type II error. A type II error is the failure to reject a false null hypothesis. In fact, a type II error is accepting the 
false alarms in the control charts as an out of control observation, while this point is not an out of control point. By reducing the type II error the power of test will be increased. Calculating the type II error for these control charts, for EDI is 0.021, for DPI 0.049, and for CPI 0.037, it can be found that this method is an accurate one to find the correct alarms.

\subsection{Case Study for Estimating the Project Final Cost}

In this section, in order to illustrate the accuracy of the introduced method, a construction project with three main phases of founding, skeleton and installation is studied. Table 9 contains all the information about this construction project, such as actual cost, the budget considered for each phase, earned value, earned money, delay in payment in months, schedule performance index, cost performance index and financial performance index. In addition, the interest rate considered is $10 \%$. The actual cost for this construction project is $1480 \$$.

Table 9. Information about a construction project

\begin{tabular}{|c|c|c|c|c|c|c|c|c|}
\hline Phase & $A C$ & BAC & EV & EM & D & EDI & CPI & FPI \\
\hline Founding & 200 & 450 & 100 & 80 & 2 & 0.8 & 0.75 & 0.5 \\
\hline Skeleton & 350 & 550 & 120 & 90 & 3 & 0.6 & 0.62 & 0.7 \\
\hline Installation & 100 & 380 & 50 & 30 & 1 & 0.82 & 0.77 & 0.6 \\
\hline
\end{tabular}

In order to make the results plainer, the final budget of this construction project was calculated with four different methods: Bagherpour's [11] method, Mortaji's [15] method, Christensen's [13] method and the newly proposed method in this paper using equation 16 . This comparison most clearly illustrates the advantage of using the new method over existing methods 


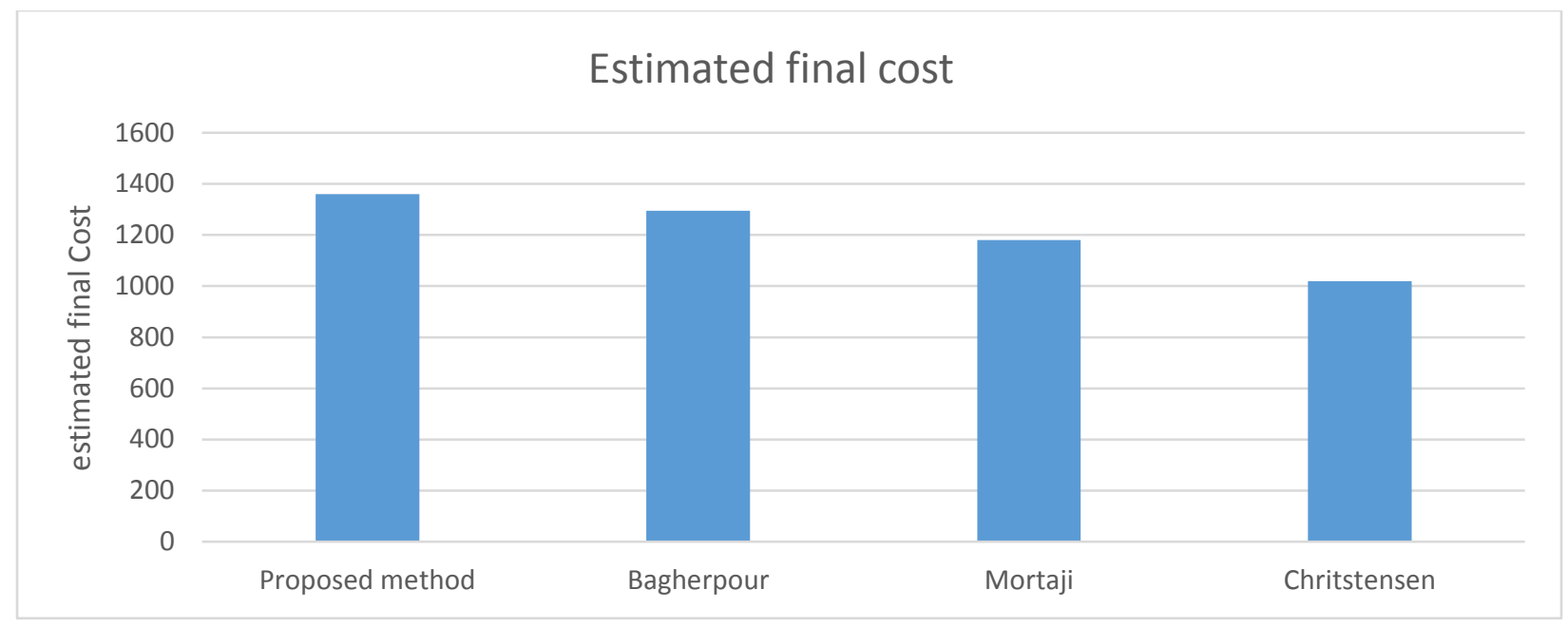

Figure 20. Estimated final cost by different methods

According to Figure 20, the new approach presented in this paper resulted in a higher estimated final budget compared to the other methods. Since the proposed method estimated $\$ 1,360$, which has the smallest variance with the actual cost $(\$ 1,480-\$ 1,360=\$ 120)$. It is clear that considering the SPI as the schedule performance index and not mentioning any financial issue, the Christensen [13] method estimate produced a result that was less than other methods, and its results may cause financial problems for a project manager using this method for estimating the final budget. However, Figure 20 does not show the clear advantage of the newly proposed method over the others. In order to have a more reliable comparison, it is better to analyze the sensitivity of each method by changing other factors, such as delay in payment and interest rate. 
Table 10. delay in payment of each phase

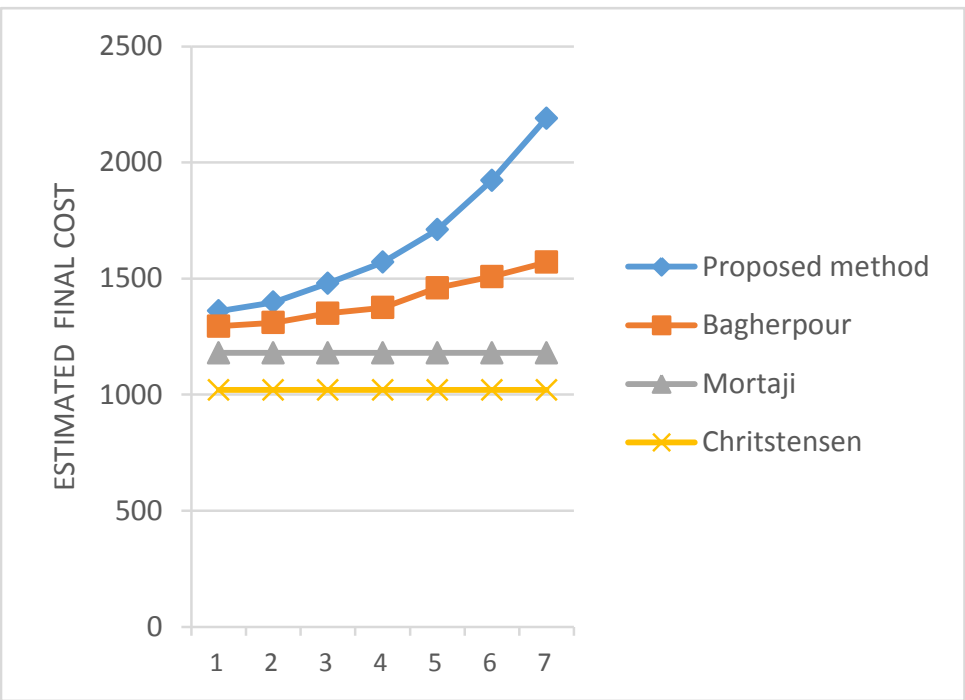

\begin{tabular}{|c|c|c|}
\hline & \multicolumn{2}{|c|}{ Delay in different phases in month } \\
\hline 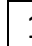 & \multicolumn{2}{|c|}{2 in phase 1,3 in phase 2, 4 in phase 3} \\
\hline 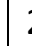 & \multicolumn{2}{|c|}{3 in phase 1,4 in phase 2,5 in phase 3} \\
\hline 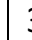 & \multicolumn{2}{|c|}{4 in phase 1,5 in phase 2,6 in phase 3} \\
\hline 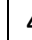 & \multicolumn{2}{|c|}{5 in phase 1,6 in phase 2,4 in phase 3} \\
\hline 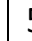 & \multicolumn{2}{|c|}{6 in phase 1,7 in phase 2,5 in phase 3} \\
\hline ( & \multicolumn{2}{|c|}{8 in phase 1,9 in phase 2,7 in phase 3} \\
\hline trata & \multicolumn{2}{|c|}{10 in phase 1,11 in phase 2,9 in phase } \\
\hline \multicolumn{3}{|c|}{ Table 11. Notation of each phase } \\
\hline & Founding & Phase1 \\
\hline & Skeleton & Phase 2 \\
\hline & Installation & Phase 3 \\
\hline
\end{tabular}

Figure 21. The effect of delay in payment on estimating final cost

Figure 21 clearly indicates that the sensitivity to delay in payment of the newly proposed method is greater than in previous methods. The Mortaji [15] and Christensen [13] methods are not at all sensitive to delay in payment and, although the Bagherpour [11] method considers the delay in payment, analyzing the whole project in one phase and using the less-reliable schedule performance index results in less trustworthy results.

Moreover, Figure 22 clearly shows that the previous methods were not sensitive to changes in interest rates, while the introduced method is. This change can be seen by changing the interest rate from $5 \%$ to $20 \%$, which causes the estimated final budget to change from $\$ 1,360$ to $\$ 1,740$. In the Bagherpour [11] method the interest rate is considered, but for the aforementioned reasons it cannot provide accurate and precise results. 


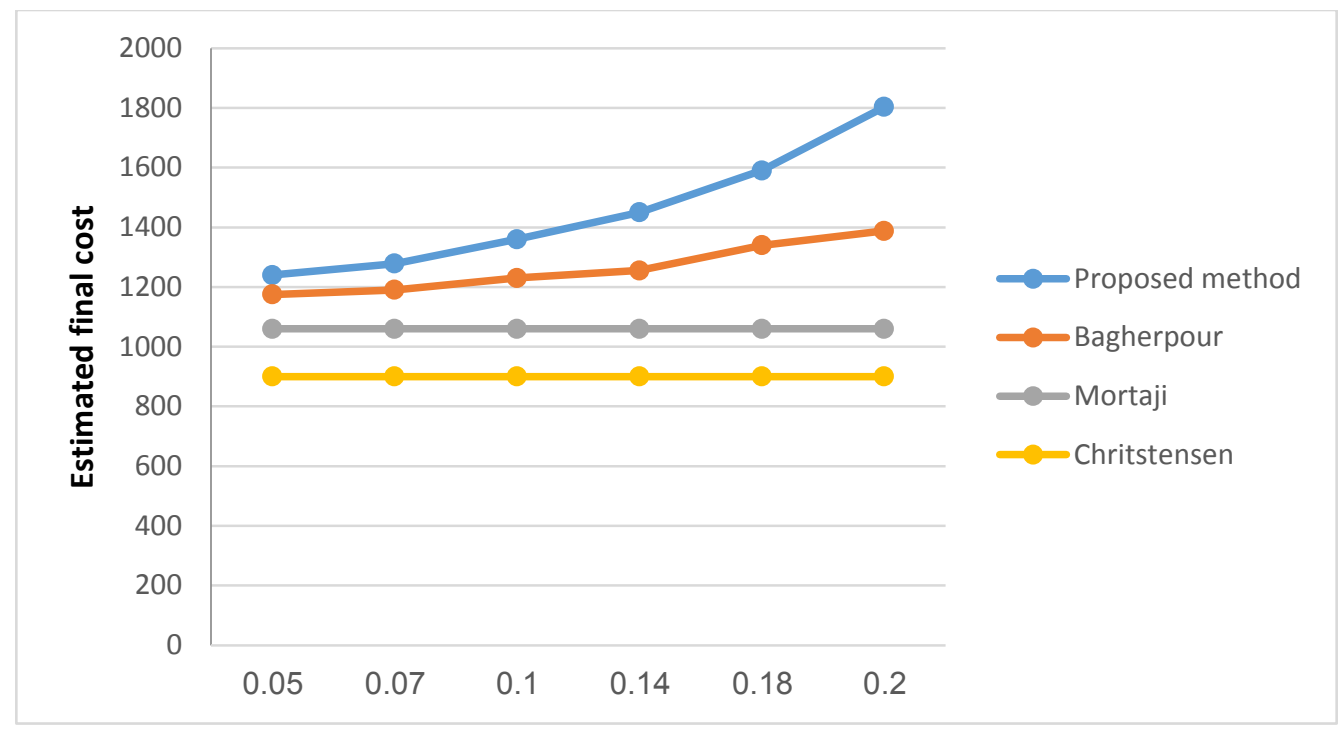

Figure 22. The effect of Interest Rate on estimating final budget 


\section{CHAPER 5. CONCLUSIONS AND RECOMMENDATIONS}

\subsection{Conclusions}

Hundreds of projects fail every year due to the lack of an accurate monitoring system. Too much of an emphasis on cost, and using cost as the main proxy for measuring project performance, provides inaccurate results, which this study sought to correct. Decoupling the cost and schedule dimensions of a project can solve the problem of traditional EVM systems in calculating the schedule and duration performance of project. In this new approach a new concept, dubbed "earned duration," is introduced to focus on the duration/schedule aspect of the project. Thus, for measuring the schedule performance of a project the EDM is used, solving the problems of SPI and SPI(t). Moreover, EVM is an excellent technique for analyzing and monitoring project performance. Although several studies have been done to improve the capability of EVM in monitoring the project cost and schedule performance, there remains a failure to provide an accepted level for cost and schedule deviations from the plan. The combination of SPC and the earned duration system can help project managers find important changes in project time and cost progress. Furthermore, this combination allows even minor trends and deviations, those that cannot be detected by simpler methods, to be detected. One of the main assumptions that should be checked before applying the SPC is the dependency of the measurements. In this study the $\mathrm{ACF}$ was used to check the dependency of cost and schedule performance index of a construction project. Their ACF shows that these indices are dependent, with different lags. Therefore, it is suggested to use one of the SPC methods for autocorrelated data. The SCCs on residuals are the control charts suggested for monitoring the cost and schedule performance of the project in this research. In order to apply SCCs on residuals, an ARIMA model should be fitted to the cost and schedule performance indices, and their residuals are calculated. Based on the ACF and PACF the best ARIMA model is suggested for each index. The ACF and PACF on their residuals show the accuracy of their respective ARIMA models. Therefore, applying the SCCs on the residuals provides the project team with project performance behavior in the form of special cause variations and the associated accepted levels. Using this newly introduced approach, warnings about future trends and even small changes can be detected, allowing the project team to find the causes of problems and improvements during the life of project. 
Delays in payment, cash flow and the time value of money are some financial aspects which have significant impacts on estimating the final budget of projects. By considering the financial aspects in estimating at completion, the results are realistic. However it is obvious that different phases of a project have different conditions, so considering them to be a monolithic system causes project managers to analyze these projects erroneously. In this study it is suggested to measure the cost, schedule and financial index of each project phase separately. Assigning diverse weights to schedule, cost and financial factors for different phases of a project can help managers create a more accurate estimate of the final budget.

\subsection{Recommendations for Further Research}

The main purpose of EVM and EDM is to predict the future of projects and monitor and analyze their cost and schedule performance. By calculating the cost and schedule performance index, project managers can monitor the overall performance of projects. Using these indices will lead them to an estimate for the final cost and duration. However, in real life there are some opaque and obscure data, uncertainties in the events and activities of projects. For providing a practical approach to predicting values in situations with no trend in previous performance, or any specific pattern, the fuzzy times series can be utilized. For example, in medical projects and drug development projects the majority of resources belong to the clinical experiments, so the exact amount of work required to calculate the performance indices is unknown. Introducing fuzzy EDM indices can provide more realistic results.

Moreover, for developing the introduced method in this study it is suggested to use other control charts for autocorrelated data and compare them to find the best method for monitoring the performance of projects. 


\section{REFERENCES}

1. Abba, Wayne. "Earned Value Management: Reconciling Government and Commercial Practices." Program Manager. Jan./Feb. 1997: 58 - 63.

2. Aliverdi, R., Naeni, L.M. and Salehipour, A., 2013. "Monitoring project duration and cost in a construction project by applying statistical quality control charts," International Journal of Project Management, 31(3), pp.411-423.

3. Alwan, Layth C., and Harry V. Roberts. "Time-series modeling for statistical process control." Journal of Business \& Economic Statistics 6.1 (1988): 87-95.

4. Anbari, F. T. (2003). Earned value project management method and extensions. [Article]. Project Management Journal, 34(4), 12-23.

5. Anbari, F. T., Lipke, W., Henderson, K., \& Zwikael, O. (2009). Prediction of project outcome: The application of statistical methods to earned value management and earned schedule performance indexes. International Journal of Project Management, 27(4), 400-407. doi: 10.1016/j.ijproman.2008.02.009

6. Bagherpour M. An Extension to Earned Value Management. Cost Management. 2011;25(3):41.

7. Barraza, G.A., Black, E., Mata, F., 2004. Probabilistic forecasting of project performance using stochastic S. curves. Journal of Management in Engineering 130 (1).

8. Book, S. A. (2006a). Earned schedule and its possible unreliability as an indicator. The Measurable News, 7.

9. Christensen DS, Christensen DS. The estimate at complete problem: a review of three studies. International Journal of Project Management. 1993;24(1):37-42.

10. Christensen, D.S., Conley, R.J., Kankey, R.D., 2003. Some empirical evidence on the nonnormality of cost variance on defense contracts. Journal of Cost Analysis \& Management 316.

11. De Marco, A., Briccarello, D., Rafele, C. (2009). "Cost and schedule monitoring of industrial building projects: Case study.” J. Constr. Eng. Manage., 135 (9), 853-862.

12. Deltek "The Basics of Earned Value Management" published in white paper by Project proven industry smart 2008. 
13. Department of Defense. POD Instruction 7000.2: Performance Measurement for Selected Acquisitions. Washington, DC: Government Printing Office, 22 Dec. 1967.

14. Department of the Navy. PERT Summary Report, Phase 1. Washington, DC: Special Projects Office, Bureau of Naval Weapons, 1958

15. Ding, B.F., and Zhang, H.G. (2006). "The improvement of earned value analysis in schedule measurement method (in Chinese).” Information Technology, 2, 14-16.

16. Fleming, Q. W., \& Koppelman, J. M. (2003). What's your project's real price tag? Harvard Business Review, 81(9), 20.

17. Fleming, Quentin W., and Joel M. Koppelman. "Earned Value Project Management" Cost Engineering. Feb. 1997: 13-15

18. Fleming, Quentin W., and Joel M. Koppelman. "The Earned Value Body of Knowledge." Proceedings of the 30th Annual Project M Philadelphia, PA: 10 Oct. - 16 Oct. 1999.

19. Fleming, Quentin W., and Joel M. Koppelman. Earned Value Project Management. 2nd ed. Upper Darby, PA: Project Management Institute, 1996

20. G. Vitner, S. Rozenes, S. Spraggett, Using data envelope analysis to compare project efficiency in a multi-project environment, International Journal of Project Management 24 (4) (2006) 323-329

21. Gorog, M.," A comprehensive model for planning and controlling contractor cash flow.’International Journal of project management , 2009, No. 27,pp. 481-492.

22. Healy, John D. "A note on multivariate CUSUM procedures." Technometrics29.4 (1987): 409-412.

23. Henderson, K. (2003). Earned schedule: A breakthrough extention to earned value theory? A retrospective analysis of real project data. The Measurable News, 6.

24. Henderson, K. (2005). Earned schedule in action. The Measurable News, 7.

\section{5. http://www.chambers.com.au/}

26. Hwee, N.G., Tiong, R.L.K., "Model on cash flow forecasting and risk analysis for contracting firms.” International Journal of Project Management,2002, No. 20 : pp. 351363.

27. Jacob, D. (2006). Is "earned schedule" an unreliable indicator No, but it's not necessarily the premier indicator for assessing schedule performance. The Measurable News, 6.

28. Jacob, D.S., and Kane M. (2004). "Forecasting schedule completion using earned value metrics revisited." The Measurable News, summer, 11-7. 
29. Khamooshi, H. and Golafshani, H., 2014. EDM: Earned Duration Management, a new approach to schedule performance management and measurement. International Journal of Project Management, 32(6), pp.1019-1041.

30. Kim, B.C., and Reinschmidt, K.F. (2010). "Probabilistic forecasting of project duration using Kalman filter and the earned value method.” J. Constr. Eng. Manage, 136 (8), 834-843.

31. Kim, Byung-cheol, and Kenneth F. Reinschmidt. "Probabilistic forecasting of project duration using Bayesian inference and the beta distribution." Journal of Construction Engineering and Management 135.3 (2009): 178-186.

32. Kwak, Young Hoon, and Frank T. Anbari. "History, practices, and future of earned value management in government: Perspectives from NASA."Project Management Journal 43.1 (2012): 77-90.

33. Kwak, Young Hoon, and Frank T. Anbari. Project Management in Government: An Introduction to Earned Value Management (EVM). IBM Center for the Business of Government, 2010.

34. Leu, S.S., Lin, Y.C., 2008. Project performance evaluation based on statistical process control techniques. Journal of Construction Engineering and Management-ASCE 134 (10), 813-819.

35. Lipke, W. (2003). Schedule is different. The Measureable News, March 2003, 5.

36. Lipke, W., 2002. A study of the normality of earned value indicators. The Measurable News 1-16 (December).

37. Lipke, W., Vaughn, J., 2000. Statistical process control meets earned value. The Journal of Defense Software Engineering 16-20 (June).

38. Lipke, W., Zwikael, O., Henderson, K., Anbari, F., 2009. Prediction of project outcome, the application of statistical methods to earned value management and earned schedule performance indexes. International Journal of Project Management 27, 400-407.

39. Maravas, A., Pantouvakis, J.P.," Project Cash flow analysis in the presence of uncertainty in activity duration and cost.” International Journal of Project Management,2012, No.30, pp.374384.

40. Mortaji ST, Bagherpour M, Noori S. Fuzzy earned value management using LR fuzzy numbers. Journal of Intelligent \& Fuzzy Systems: Applications in Engineering and Technology. 2013 Mar 1;24(2):323-32. 
41. Moslemi Naeni, L., Shadrokh, S.H., Salehipour, A., 2011. A fuzzy approach for the earned value management. International Journal of Project Management 29 (6), 764-772.

42. Naeni, L.M., Shadrokh, S., Salehipour, A. (2011). "A fuzzy approach for the earned value management.” Int. J. Proj. Manage., 29 (6), 764-772.

43. Roberts, S. W. "Control chart tests based on geometric moving averages."Technometrics 42.1 (2000): 97-101.

44. Salari, Mostafa, Nooshin Yousefi, and Mohhmad Mahdi Asgary. "Cost Performance Estimation in Construction Projects Using Fuzzy Time Series."International Journal of Information Technology Project Management (IJITPM) 6.1 (2015): 66-75.

45. Solomon, P.J., and Young R.R. (2007). Performance-based earned value. J. Wiley \& Sons, Inc., Hoboken, New Jersey.

46. Song, L. (2010). Earned value management: A global and cross-industry perspective on current EVM practice. Newtown Square, PA: Project Management Institute.

47. Steyn, H., 2008. A framework for managing quality on system development projects. Portland International Conference on Management of Engineering and Technology 1-5, 1295-1302.

48. Valle, J.A., and Soares, C.A.P. (2006). "The use of earned value analysis (EVA) in the cost management of construction projects." PMI Global Congress EMEA.

49. Vanhoucke, M. (2011). "Measuring the efficiency of project control using fictitious and empirical project data.” Int. J. Proj. Manage, In press.

50. Vanhouckel, M., \& Vandevoorde, S. (2007). A simulation and evaluation of earned value metrics to forecast the project duration. The Journal of the Operational Research Society, 58(10), 1361-1374.

51. W. A. Shewhart, Economic Control of Quality of Manufactured Product. Princeton, NJ: Van Nostrand Reinhold (1931).

52. Wei, William Wu-Shyong. Time series analysis. Reading: Addison-Wesley publ, 1994. 


\section{APPENDIX 1}

Table 12 shows the CPI, DPI, and EDI of the construction project which is calculated in 42 weeks.

Table 12. Cost and schedule performance indices of a construction project

\begin{tabular}{|c|c|c|c|}
\hline week & EDI & DPI & $\mathrm{CPI}$ \\
\hline 1 & 0.977142857 & 1 & 0.670942 \\
\hline 2 & 0.487380952 & 1 & 0.50416 \\
\hline 3 & 0.602738095 & 0.7 & 0.760356 \\
\hline 4 & 0.833619048 & 0.75 & 0.759213 \\
\hline 5 & 0.89468254 & 0.8 & 0.763602 \\
\hline 6 & 0.629293155 & 1 & 0.764706 \\
\hline 7 & 0.619968332 & 0.857142857 & 0.733611 \\
\hline 8 & 0.686144435 & 0.875 & 0.7368 \\
\hline 9 & 0.681304082 & 0.777777778 & 0.799442 \\
\hline 10 & 0.617877027 & 0.8 & 0.797347 \\
\hline 11 & 0.671493711 & 0.727272727 & 0.816336 \\
\hline 12 & 0.665205041 & 0.666666667 & 0.81403 \\
\hline 13 & 0.613075743 & 0.692307692 & 0.800804 \\
\hline 14 & 0.643248103 & 0.642857143 & 0.76786 \\
\hline 15 & 0.63191467 & 0.666666667 & 0.784256 \\
\hline 16 & 0.622062769 & 0.625 & 0.790276 \\
\hline 17 & 0.618980687 & 0.705882353 & 0.803395 \\
\hline 18 & 0.676243825 & 0.888888889 & 0.809461 \\
\hline 19 & 0.748261058 & 0.842105263 & 0.773147 \\
\hline 20 & 0.732740866 & 0.8 & 0.741077 \\
\hline 21 & 0.681775072 & 0.761904762 & 0.7134 \\
\hline 22 & 0.697482478 & 0.818181818 & 0.711023 \\
\hline 23 & 0.704404372 & 0.826086957 & 0.716156 \\
\hline 24 & 0.769525694 & 0.833333333 & 0.743043 \\
\hline 25 & 0.754491769 & 0.8 & 0.763827 \\
\hline 26 & 0.714519106 & 0.769230769 & 0.769211 \\
\hline 27 & 0.735163189 & 0.777777778 & 0.780497 \\
\hline 28 & 0.724128221 & 0.75 & 0.799218 \\
\hline 29 & 0.74522791 & 0.75862069 & 0.809304 \\
\hline 30 & 0.769763467 & 0.766666667 & 0.820016 \\
\hline 31 & 0.803859257 & 0.806451613 & 0.833095 \\
\hline 32 & 0.812773338 & 0.78125 & 0.85031 \\
\hline 33 & 0.817561242 & 0.757575758 & 0.854605 \\
\hline 34 & 0.817725878 & 0.764705882 & 0.849938 \\
\hline 35 & 0.838144987 & 0.742857143 & 0.857922 \\
\hline 36 & 0.844356167 & 0.722222222 & 0.883706 \\
\hline
\end{tabular}




\begin{tabular}{|l|l|l|l|}
37 & 0.87194814 & 0.72972973 & 0.898708 \\
38 & 0.870310027 & 0.710526316 & 0.907859 \\
39 & 0.870310027 & 0.692307692 & 0.917011 \\
40 & 0.874450814 & 0.675 & 0.929664 \\
41 & 0.895154747 & 0.682926829 & 0.944191 \\
42 & 0.893272572 & 0.666666667 & 0.958924 \\
\hline
\end{tabular}




\section{APPENDIX 2}

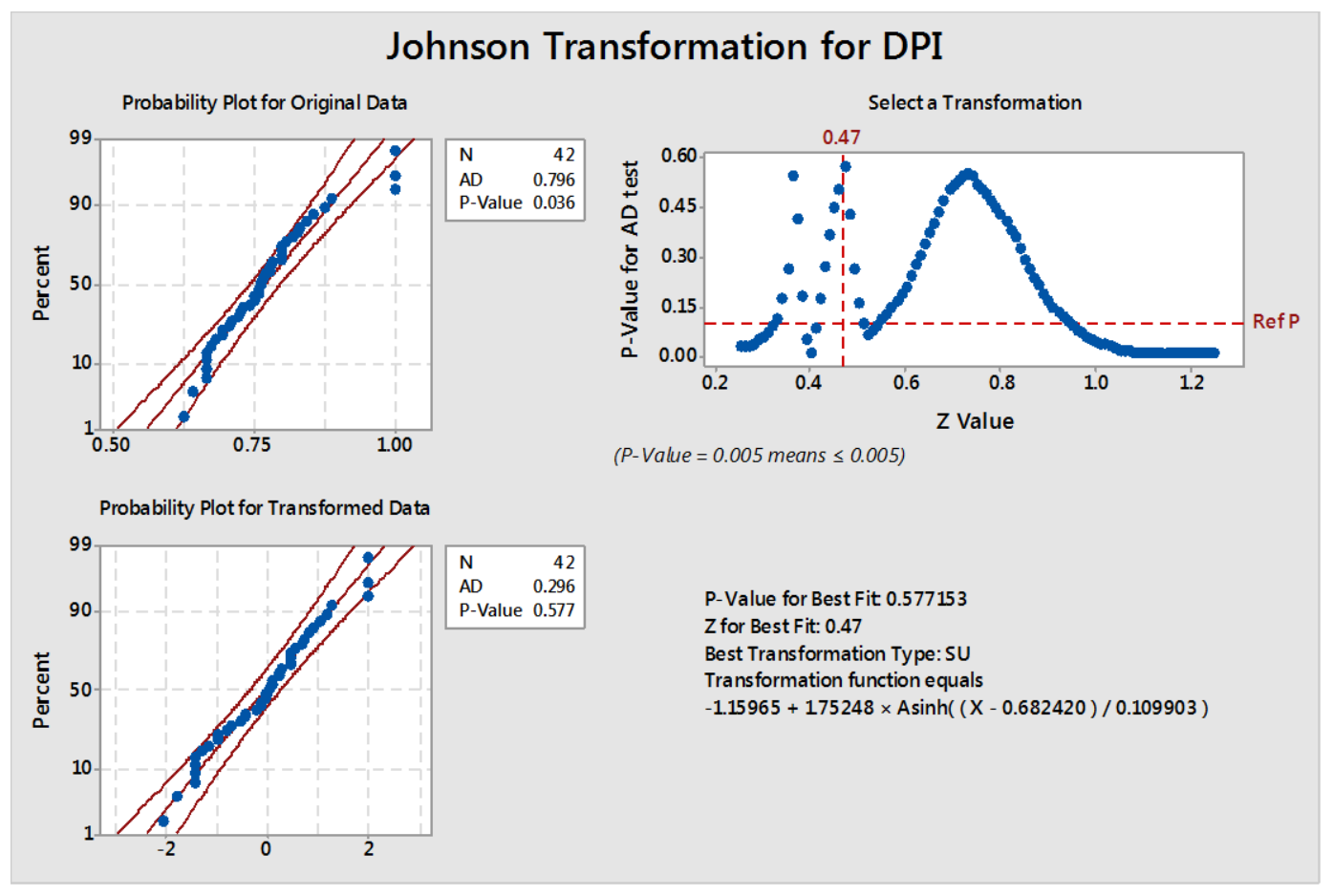

Figure 23. Summary of Johnson transformation for DPI

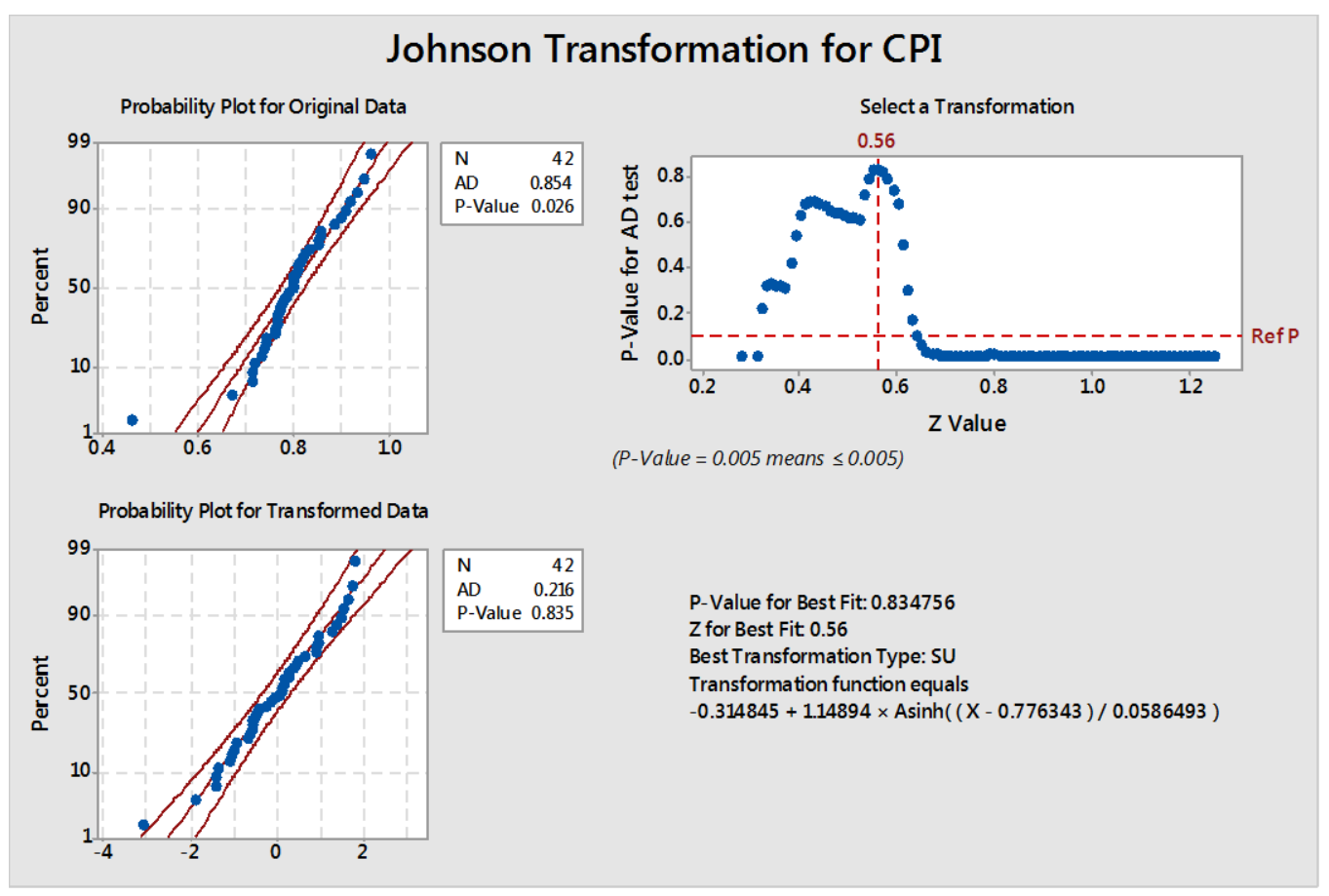

Figure 24. Summary of Johnson transformation for CPI 
Table 13. EDM indices and their transformation

\begin{tabular}{|c|c|c|c|c|c|}
\hline week & $\mathrm{CPI}$ & EDI & DPI & $\begin{array}{c}\text { CPI } \\
\text { transformed }\end{array}$ & DPI transformed \\
\hline 1 & 0.670942 & 0.977143 & 1 & -1.864822377 & 1.964944183 \\
\hline 2 & 0.460851 & 0.487381 & 1 & -3.054187632 & 1.964944183 \\
\hline 3 & 0.760356 & 0.602738 & 0.666667 & -0.62428564 & -1.41 \\
\hline 4 & 0.759213 & 0.833619 & 0.75 & -0.645833321 & -0.140475539 \\
\hline 5 & 0.763602 & 0.894683 & 0.8 & -0.562518331 & 0.47 \\
\hline 6 & 0.764706 & 0.629293 & 1 & -0.541349138 & 1.964944183 \\
\hline 7 & 0.733611 & 0.619968 & 0.857143 & -1.091462232 & 1.019658581 \\
\hline 8 & 0.7368 & 0.686144 & 0.875 & -1.040316819 & 1.165928363 \\
\hline 9 & 0.799442 & 0.681304 & 0.777778 & 0.126712165 & 0.215392463 \\
\hline 10 & 0.797347 & 0.617877 & 0.8 & 0.088298165 & 0.47 \\
\hline 11 & 0.816336 & 0.671494 & 0.727273 & 0.41791274 & -0.462945101 \\
\hline 12 & 0.81403 & 0.665205 & 0.666667 & 0.380260513 & -1.41 \\
\hline 13 & 0.800804 & 0.613076 & 0.692308 & 0.151433927 & -1.002199833 \\
\hline 14 & 0.76786 & 0.643248 & 0.642857 & -0.480455372 & -1.777626425 \\
\hline 15 & 0.784256 & 0.631915 & 0.666667 & -0.160301449 & -1.41 \\
\hline 16 & 0.790276 & 0.622063 & 0.625 & -0.044399797 & -2.038019013 \\
\hline 17 & 0.803395 & 0.618981 & 0.705882 & 0.197915139 & -0.788315703 \\
\hline 18 & 0.809461 & 0.676244 & 0.888889 & 0.303636951 & 1.272802598 \\
\hline 19 & 0.773147 & 0.748261 & 0.842105 & -0.377436352 & 0.88791806 \\
\hline 20 & 0.741077 & 0.732741 & 0.8 & -0.969677053 & 0.47 \\
\hline 21 & 0.7134 & 0.681775 & 0.761905 & -1.385898145 & 0.017293171 \\
\hline 22 & 0.711023 & 0.697482 & 0.818182 & -1.41732766 & 0.660064687 \\
\hline 23 & 0.716156 & 0.704404 & 0.826087 & -1.348661422 & 0.738004282 \\
\hline 24 & 0.743043 & 0.769526 & 0.833333 & -0.936424727 & 0.807110201 \\
\hline 25 & 0.763827 & 0.754492 & 0.8 & -0.558213289 & 0.47 \\
\hline 26 & 0.769211 & 0.714519 & 0.769231 & -0.454228385 & 0.110454668 \\
\hline 27 & 0.780497 & 0.735163 & 0.777778 & -0.233532941 & 0.215392463 \\
\hline 28 & 0.799218 & 0.724128 & 0.75 & 0.12261793 & -0.140475539 \\
\hline 29 & 0.809304 & 0.745228 & 0.758621 & 0.300941817 & -0.025440316 \\
\hline 30 & 0.820016 & 0.769763 & 0.766667 & 0.476610164 & 0.078187807 \\
\hline 31 & 0.833095 & 0.803859 & 0.806452 & 0.671307582 & 0.539231823 \\
\hline 32 & 0.85031 & 0.812773 & 0.78125 & 0.896776978 & 0.256886384 \\
\hline 33 & 0.854605 & 0.817561 & 0.757576 & 0.948129698 & -0.039163621 \\
\hline 34 & 0.849938 & 0.817726 & 0.764706 & 0.892238939 & 0.053266591 \\
\hline 35 & 0.857922 & 0.838145 & 0.742857 & 0.986578734 & -0.238894298 \\
\hline 36 & 0.883706 & 0.844356 & 0.722222 & 1.253694743 & -0.53809421 \\
\hline 37 & 0.898708 & 0.871948 & 0.72973 & 1.387441315 & -0.426814401 \\
\hline 38 & 0.907859 & 0.87031 & 0.710526 & 1.462652757 & -0.716226389 \\
\hline 39 & 0.917011 & 0.87031 & 0.692308 & 1.533621262 & -1.002199833 \\
\hline 40 & 0.929664 & 0.874451 & 0.675 & 1.625517258 & -1.277881558 \\
\hline 41 & 0.944191 & 0.895155 & 0.682927 & 1.72319856 & -1.151572345 \\
\hline 42 & 0.958924 & 0.893273 & 0.666667 & 1.814855292 & -1.41 \\
\hline
\end{tabular}




\section{APPENDIX 3}

Table 14. Residuals of ARIMA model for CPI, EDI, and DPI.

\begin{tabular}{|c|c|c|}
\hline DPI residuals & EDI residuals & CPI residuals \\
\hline 0.502121063 & -0.02117246 & -0.947506484 \\
\hline-2.821201001 & 0.013140106 & 1.786867697 \\
\hline 0.532806517 & -0.103877793 & 0.757067134 \\
\hline 0.342696546 & -0.06327539 & -0.502942621 \\
\hline 1.466953424 & 0.124785669 & 0.386948555 \\
\hline-0.36357939 & -0.050368662 & -0.88600775 \\
\hline 0.408363802 & -0.096750649 & -0.004075225 \\
\hline-0.595721049 & -0.175330648 & 0.909839427 \\
\hline 0.271432997 & 0.061998393 & 0.23756974 \\
\hline-0.797802914 & 0.002913686 & -0.033876465 \\
\hline-1.158651854 & -0.029823709 & 0.21862541 \\
\hline-0.181047235 & -0.068217444 & -0.556018082 \\
\hline-1.228349126 & 0.054291145 & -0.61045271 \\
\hline-0.411419375 & -0.08219297 & -0.108778893 \\
\hline-1.300811142 & -0.008378015 & 0.239145883 \\
\hline 0.29377061 & -0.004272483 & -0.090577601 \\
\hline 1.550499893 & 0.024623995 & 0.220600231 \\
\hline-0.094696017 & 0.084718564 & -0.924156701 \\
\hline-0.244792772 & 0.038823198 & -0.731351703 \\
\hline-0.418222527 & 0.025224354 & -0.758859597 \\
\hline 0.514790679 & 0.001981604 & -0.183270065 \\
\hline 0.21266167 & -0.051886017 & -0.205646818 \\
\hline 0.260154226 & 0.051693552 & 0.362304018 \\
\hline-0.089207649 & 0.021415648 & 0.260348682 \\
\hline-0.212694491 & -0.010340896 & 0.141699277 \\
\hline 0.134536828 & 0.029349065 & 0.066801598 \\
\hline-0.266723412 & -0.071885884 & 0.39731061 \\
\hline
\end{tabular}




\begin{tabular}{|r|r|r|}
\hline 0.084261018 & 0.019197181 & 0.069394608 \\
\hline 0.132094303 & 0.027360104 & 0.167019948 \\
\hline 0.548456966 & 0.037734802 & 0.080292397 \\
\hline 0.010760874 & 0.049843485 & 0.217316463 \\
\hline-0.078907893 & 0.028856902 & -0.063122176 \\
\hline 0.222683046 & 0.019623387 & -0.108080343 \\
\hline-0.100125512 & 0.011518561 & -0.069239597 \\
\hline-0.194301653 & 0.011408137 & 0.221107906 \\
\hline 0.119989056 & 0.033267091 & 0.022639392 \\
\hline-0.220138751 & 0.018309078 & 0.019596961 \\
\hline-0.31153697 & 0.00817865 & -0.049395181 \\
\hline-0.401544374 & 0.013527176 & 0.030082324 \\
\hline-0.10293004 & 0.003306256 & -0.031014331 \\
\hline
\end{tabular}

